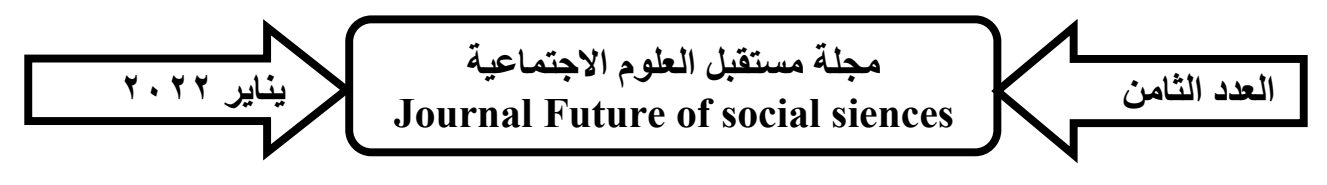

تحديات الإعلام الرياضي في هواجهة التحول الرقمي الحديث

Sports media challenges in a confrontation of modern digital transformation

$$
\begin{aligned}
& \text { د/ سهيل هممد الاسونجي. } \\
& \text { دكتوراه في التدريب الرياضي } \\
& \text { كلية التربية الرياضية - جامعة حلوان }
\end{aligned}
$$

$$
5 r+r r
$$




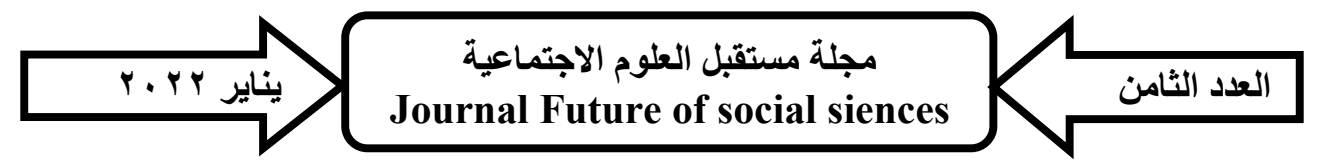




\section{العدد الثامن \\ تحديات الإعلام الرياضي في مواجهة التحول الرقمي الحديث}

الملخص:

يعتبر الإعـلام الرياضـي قديما وحديثا بمثابـة المدرسـة العامـة التي توصـل عمـل

المؤسسات الرياضية المختلفة كالأندية ومراكز الثباب والمدارس بمراحلها المختلفة وتتجاوزها فتقرب الفروق بين النـاس عن طريق مـا تتشـره بينهم من خبرات تعدل بين سلوكهم كبارا وصغارا بما يتلاءم مع القيم والتقاليد الرياضية السليمة.

وفي ظل التقدم العلمي والتكنولوجي الكبير والسريع في المجال الرياضسي والذي يبرز أهمية الإعلام الرياضي وضرورة إحاطة الأفراد بالمجتمع علما بكل ما يدور من أحداث

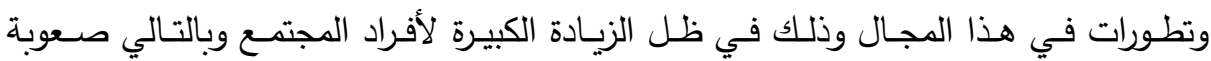
الاتصال المباشر بمصادر المعلومات والأخبار .

ويهدف البحث إلى تحديد بعض التحديات التي تواجه الاعلام الرياضي في ظل التطور التكنولوجي في التحول الرقمي الحديث، كما يهدف إلى الإجابة على بعض التساؤلات الخاصة بكيفية مواجهة التحول الرقمي الحديث في مجال الاعلام الرياضي.

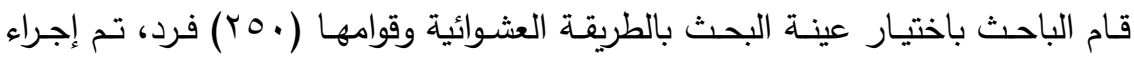

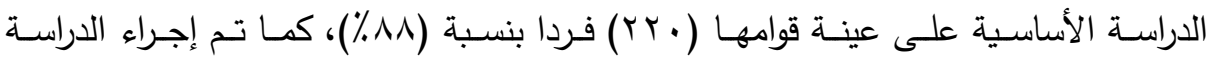
الاستطلاعية على عينـة قوامها ( •r) فردا بنسبة (r (\%)، من نفس مجتمـع البحث وخـارج العينة الاساسية.

وقد استتج الباحث أن زيادة الوعي لاى أفراد المجتمع بمعرفة ما هو التحول الرقمي وما هي استخداماته، وأن تطوير أداء العاملين في مجال الإعلام الرياضـي على أدوات التحول الرقمي الحديثة، وأنـه يجب عمل اختبارات دوريـة لكل العاملين في مجال الإعـلام الرياضـي للوقوف على مدى معرفتهم وتثقيفهم.

Sports media challenges in a confrontation of modern digital transformation

\section{Abstract:}

The sports media, old and new, is considered a public school that connects the work of various sports institutions, such as clubs and youth centers, and even educational centers in their various stages and goes beyond them, bringing the differences between people through what it publishes among them of experiences that modify their 


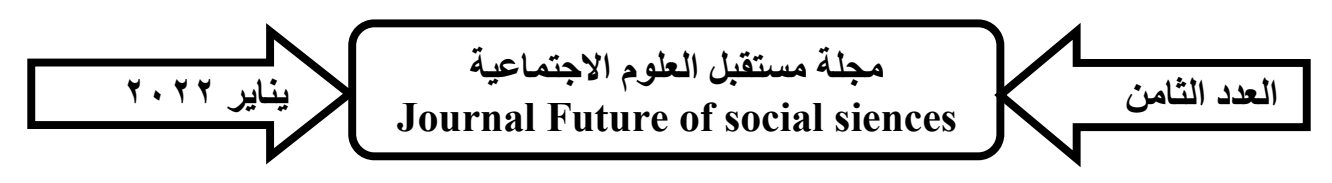

behavior, old and young, in line with sound sports values and traditions.

Sports media has a large and important role through its various means (readable, audio and visual), as it contributes significantly to highlighting the importance of physical and sports education, raising the level of sports culture to the public and increasing sports awareness for them.

The research aims to identify some of the challenges facing sports media in light of the technological development in the modern digital transformation and answering some questions about how to face the modern digital transformation in the field of sports media.

The researcher chose the research sample randomly and consisted of (250) individuals, the basic study was conducted on a sample of (220) individuals at a rate of (88\%), and the exploratory study was conducted on a sample of (30) individuals at a rate of (12\%), from the same the research community and outside the main sample.

The researcher found Increasing awareness among community members of what is digital control and what are its uses and developing the performance of sports media workers on modern digital transformation tools and Periodic tests should be done for all those working in the field of sports media to determine the extent of their knowledge and education.

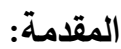

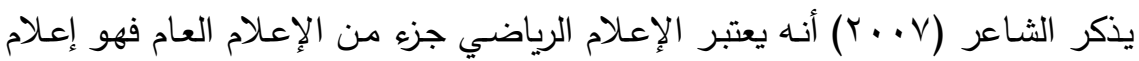

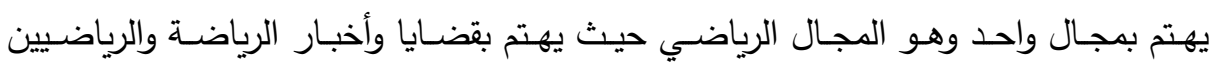

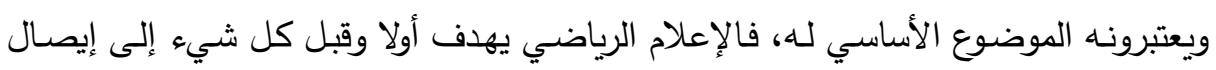

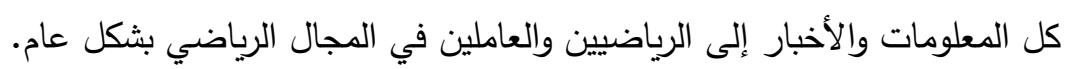

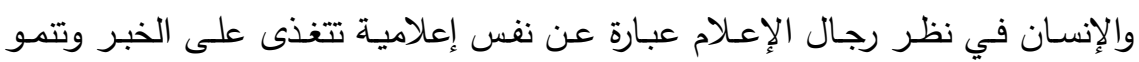

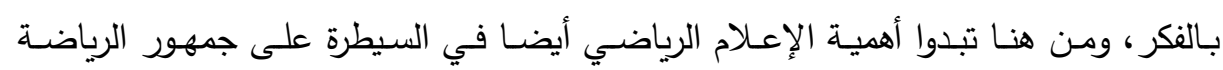

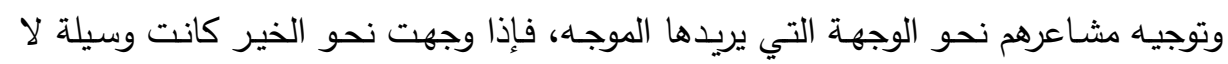

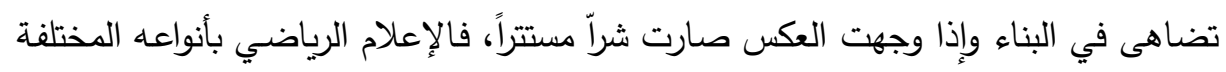

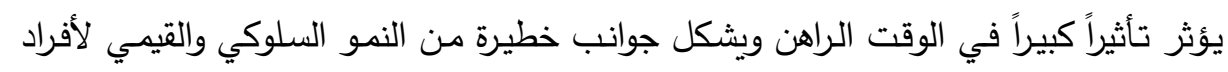

المجتمع في المجال الرياضي. 


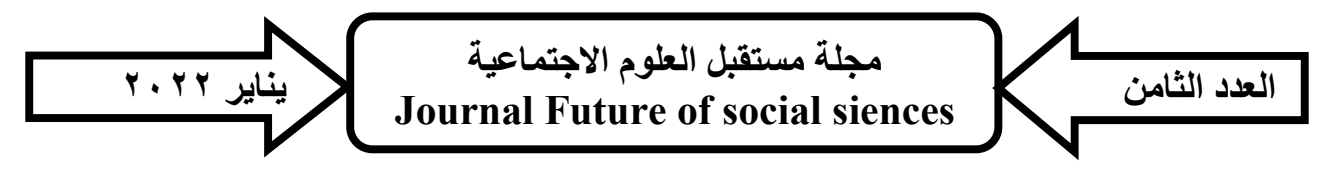

وللإعلام الرياضي دور كبير ومهم عبر وسائله المختلفة (المقروءة والمسموعة والمرئية)

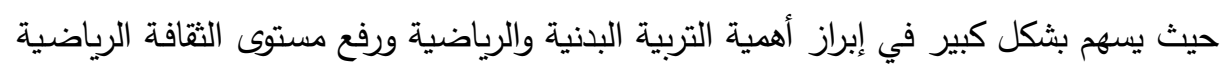

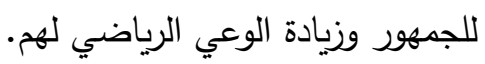
مثكلة البحث:

توجد العديد من التحديات للإعـلام الرياضـي في مواجهة التحول الرقمي والتكنولوجيا

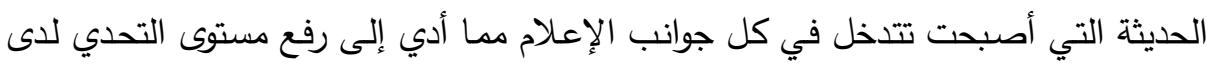

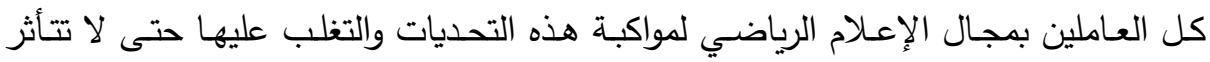
الأيدي العاملة ولا يتأثر الجمهور المتلقي.

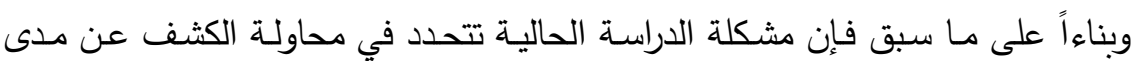
التحديات التي تواجه الإعلام الرياضي بعد الطفرة العلمية والتكنولوجية الحديثة، وإيجاد حلول لهذه التحديات. هدف البحث:

1- يهدف البحث إلى تحديد بعض التحديات التي تواجه الإعلام الرياضي في ظل التطور التكنولوجي في التحول الرقمي الحديث وينشق من الهدف الأول عدة أهداف فرعية مثل: - التعرف علي التحديات التكنولوجية علي القائمين بالإعلام الرياضي. لإني. - التعرف علي التحديات المادية علي القائمين بالاتصال. r- التعرف علي التساؤلات المطروحة عن كيفية مواجهة التطور التكنولوجي في الإعلام الرياضي. r- التعرف علي الإجابات على بعض التساؤلات الخاصـة بكيفيـة مواجهة التحول الرقـي

$$
\text { تساؤلات البحث: الحيث مجال الإعلام الرياضي. }
$$

1- ما أكثر التحديات التي تواجه العاملين بمجال الإعلام الرياضي في ظل انتثار التحول

$$
\text { الرقمي؟ }
$$

r- ما أنواع التحولات والتطورات الحديثة التي حدثت في مجال الإعلام الرياضي؟

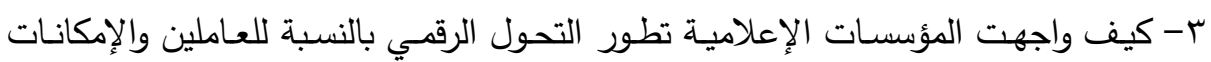

التقنية؟

ع- ما الحلول العلمية والعملية لمواكبة التحول الرقمي الحديث بالنسبة للمؤسسات والأفراد؟ 


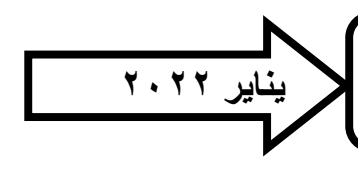

\section{مجلة مستقبل العلوم الاجتماعية Journal Future of social siences}

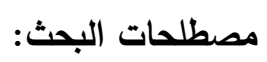

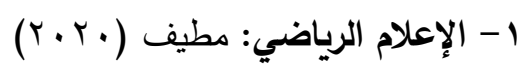

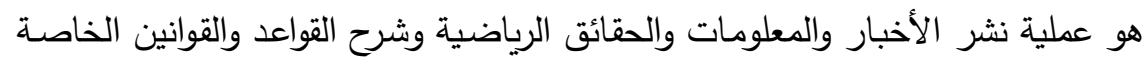

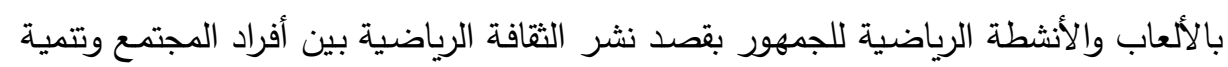
وعيه الرياضي.

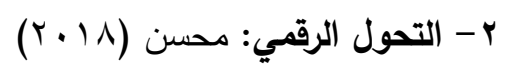

هو عملية تطبيق التقنيات الرقمية لتجديد طريقة إنجاز الأعمال وإبداع قيمة جديدة.

الإطار النظري:

لأن الإعلام الرياضي يخاطب فئة كبيرة من المجتمع بجميع طبقاته وفئاته العمرية فإنه

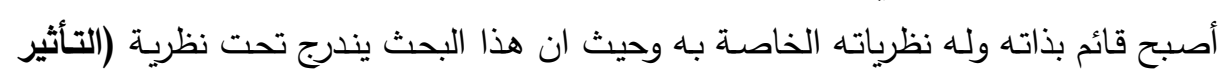
المباشر) فإن الباحث سوف يستعرض هذه النظرية: نظرية التأثير المباشر:

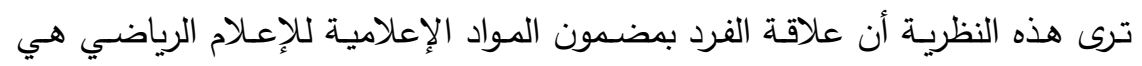
علاقة تأثير مباشر وتلقائي حيث أن التحول الرقمي قد ساعد في تطوير طرق عرض الإن المواد الإعلامية سواء كانت صحفية أو تليفزيونية أو إذاعية.

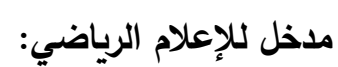

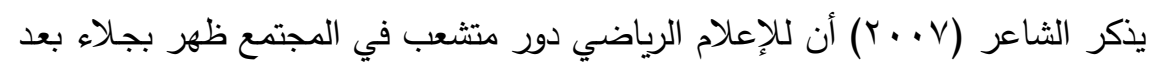

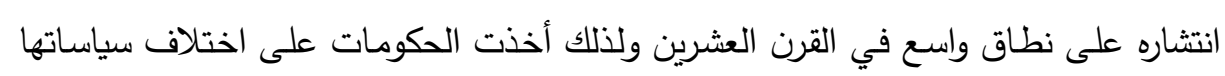

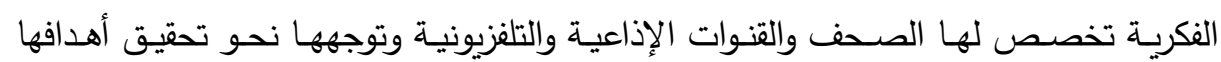

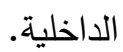

\section{تعريف الإعلام الرياضي:}

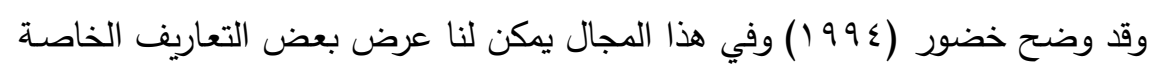

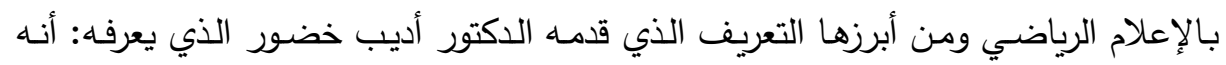

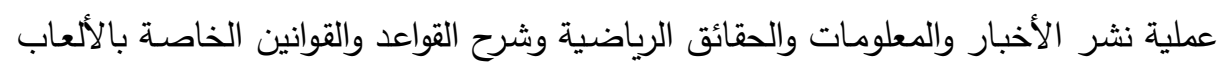
والأنثطة الرياضية بقصد نثر الثقافة الرياضية بين أفراد المجتمع وتتمية وعيه الرياضي. 


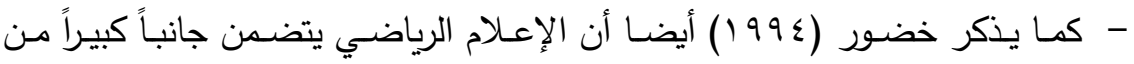

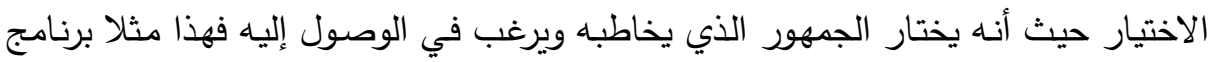

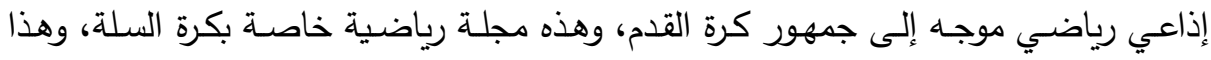
حديث تلفزيوني موجه إلى جمهور كرة اليد وهكذا.

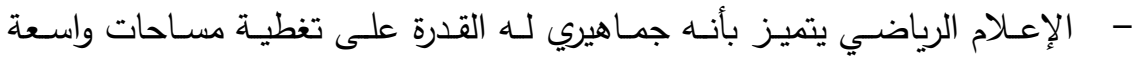
ومخاطبة قطاعات كبيرة من الجماهير .

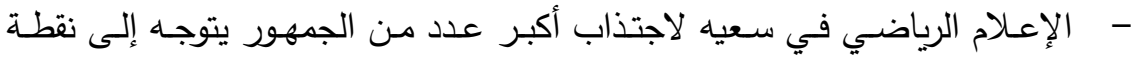

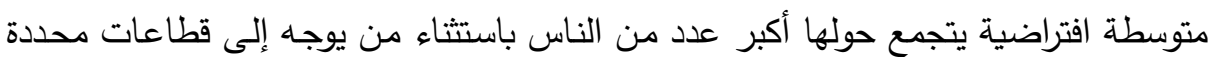
من الناس كالبرامج الرياضية للمعوقين وغيرها. - الإعلام الرياضي بوسائله المختلفة مؤسسة اجتماعية يستجيب إلى البيئة التي يعمل البئل

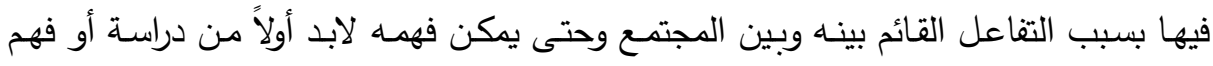

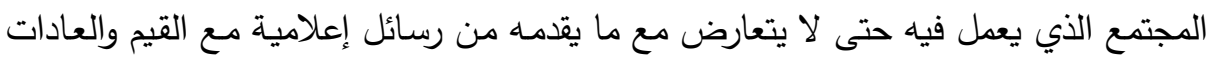

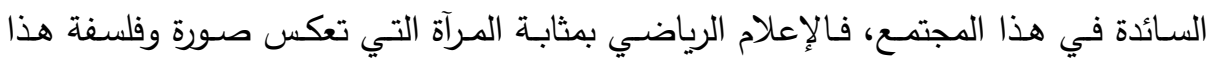

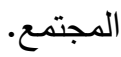
أهمية الإعلام الرياضي:

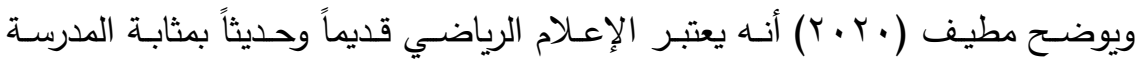

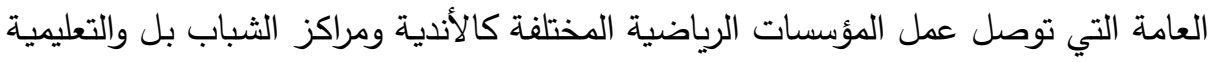
فتتجاوزها فتقرب الفروق بين الناس عن طريق ما تتشره بينهم من خبرات تعدل بين سلوكهم كبارا وصغارا بما يتلاءم دع القيم والتقاليد الرياضية السليمة.

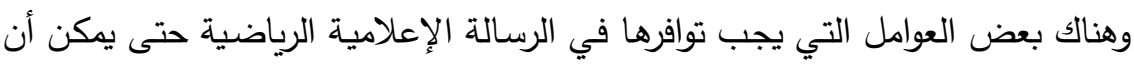

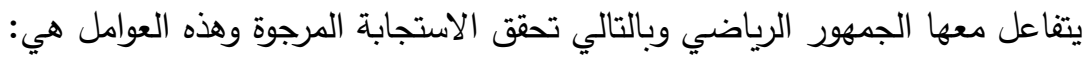

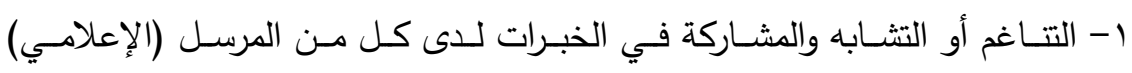
والمستقبل (الجمهور) بما يضمن فهم الرموز ومعرفتها وبالتالي الاستجابة لها. r- استثارة انتباه الجمهور واستعمال رموز واضحة ومفهومة.

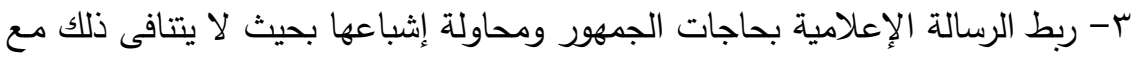
العادات والتقاليد والقيم الرياضية النبيلة. 


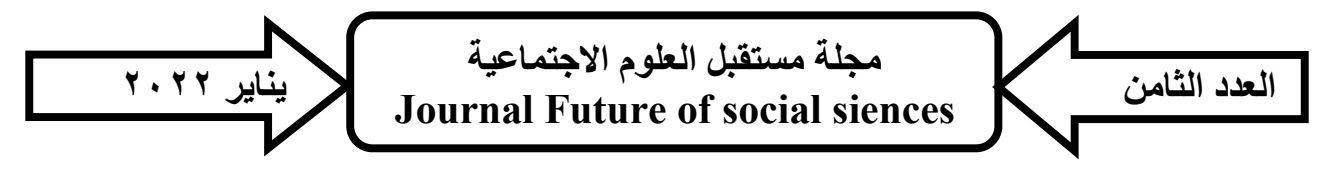

ع - مراعاة الحالتة النفسية للجمهور ومراعاة الدقة في اختيار الوقت المناسب والمكان الملائم والوسيلة المجدية حسب نوع وقدرة الجمهور • ماهر 0- الاهتمـام باستخدام قواعد اللغـة التي يخاطب بها الجمهور بمـا يتتاسب مـع درجـة فهمهم لها وبما يتتاسب مـع مستواه الثقافي والتعليمي ويفضّل استخدام اللغـة الإعلامية وهي التي تجمع ما بين اللغة الفصحى والعامية. مدخل للتحول الرقمي: قد نجم عن الثورة الرقمية تطور في الحياة الإنسانية، وتغير اجتماعي لحياة الأفراد، وغرس كثير من الأفكار الجديدة لديهم نحو التعليم الرقمي، وأصبح هذا النوع من التعليم له دور في التوظيف الاجتمـاعي، وحل مشكلات الفرد في المجتمع من خـلال الاعتمـاد على

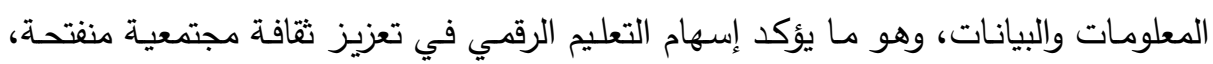
ولديها من المقومات ما يجعلها تساهم في عملية التطوير بعيدا عن منظور التلقي.

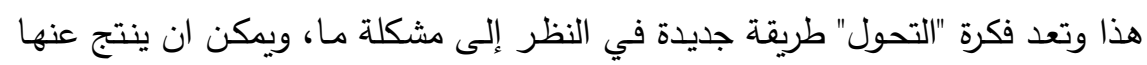
حلول فريدة مبتكرة وإبداعات حقيقية، تساعد في الحصول على أفكار وأساليب جديدة لمواجهة متطلبات القرن الحادي والعشرين. تعريف التحول الرقمي: يذكر كل من عويس وعبدالرحيم (1991 1 ) أنه هو عملية تطبيق التقنيات الرقمية لتجديد طريقة إنجاز الأعمال وإبداع قيمة جديدة وتقديمها. فوائد التحول الرقمي: ت التمان - تحديث نماذج العمل لمواكبة التطورات التكنولوجية الحاصلة. - تعزيز كفاءة العمليات وتخفيض نسبة الأخطاء والهفوات. - تعزيز رضا الموظفين والعملاء على حد سواء. - تعزيز الإيرادات المحققة من الاستثمارات.

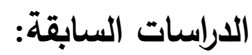

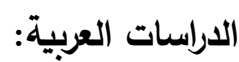

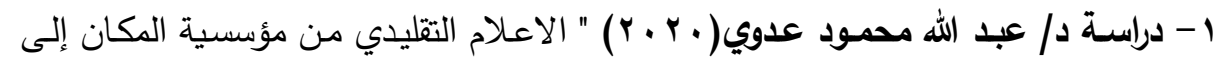
مؤسسية البيئة الافتراضية: ماجيتستير"

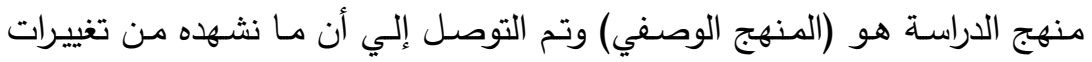

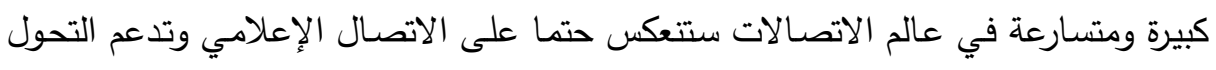
في العمل المؤسسي الإعلامي الى الرقمية. 


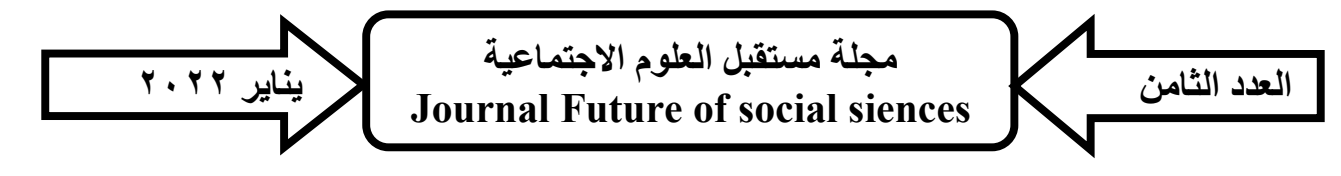

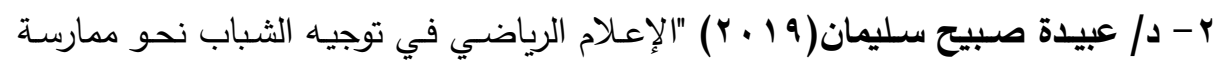

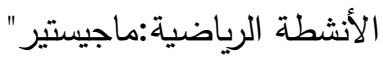

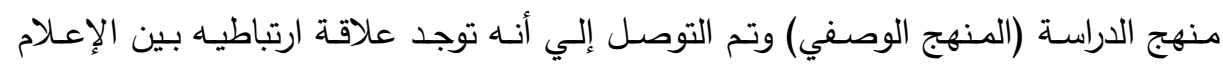

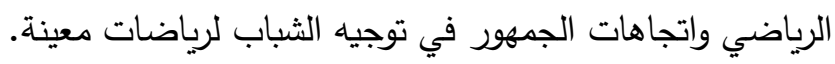

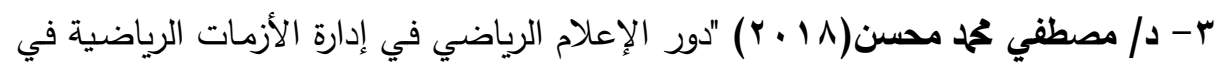

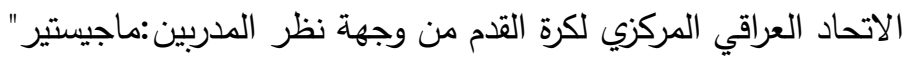

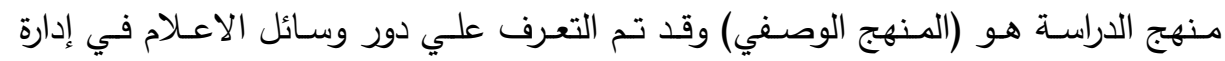

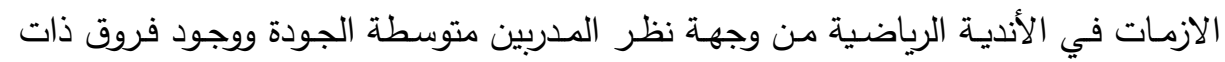

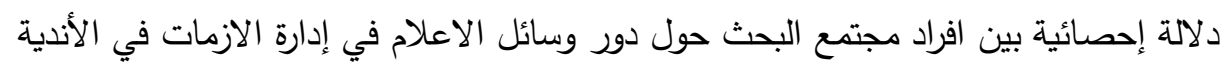
الرياضية من وجهة نظر المدربين.

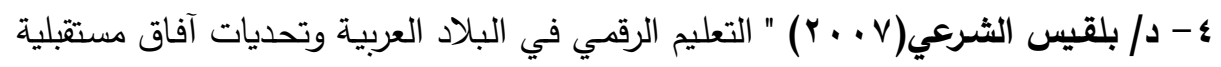

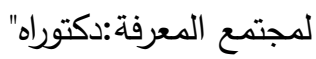

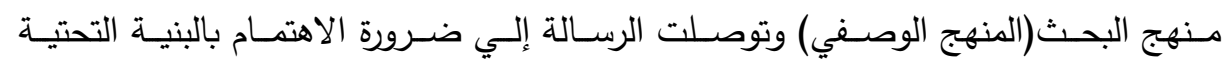

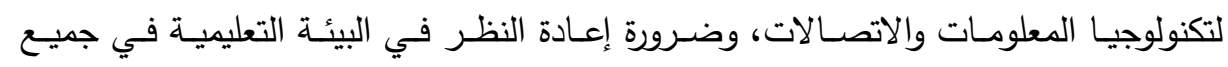

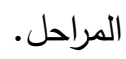

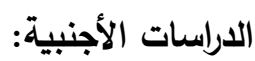

1- Elliot Tiffany and Kay, Marianne and Laplante(2016) "Digital Transformation in Higher Mary Education. How Content Management Technologies and Practices Are Evolving in the Era of Experience Management "

منهج البحث (المنهج الوصفي) وقد نتج عنها أن رؤساء الجامعات سيكون لديهم القدرة على القى

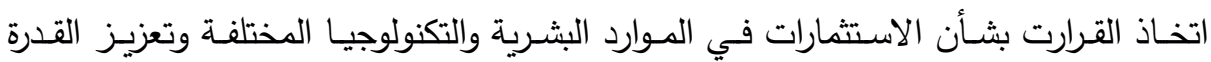

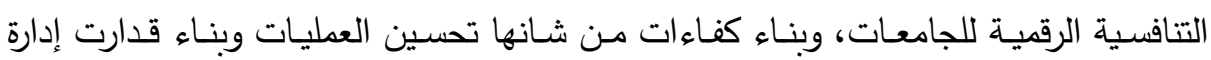
الخبرات build experience capabilities.

2- Lahtinen, M.and Weaver, B (2015) "Educating for a digital future - Walking three roads simultaneously: one analog and two digital " منهج البحث (المنهج الوصفي) وقد عرضت الدراسة تحدي التحول الرقمي وقد اشارت الدراسة

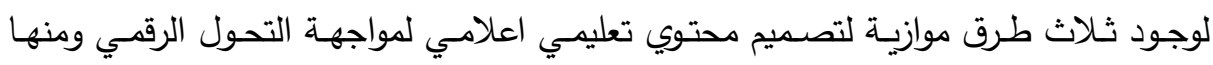
تتشيط الأنثطة التعليمية غير الرقمية التي تعمل على محو الامية الرقمية. 


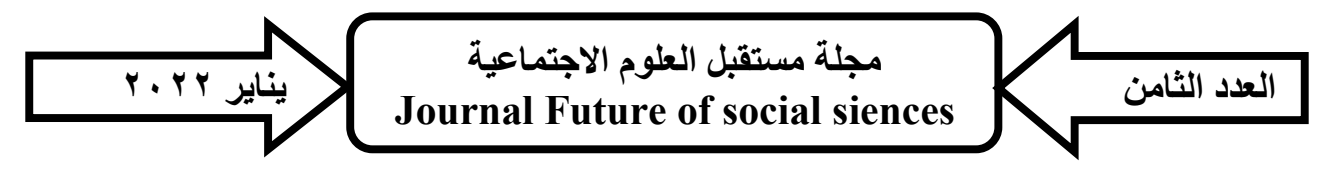

التعليق على الاراسات السابقة:

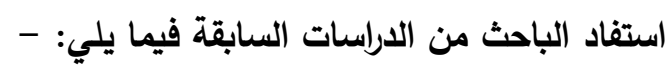

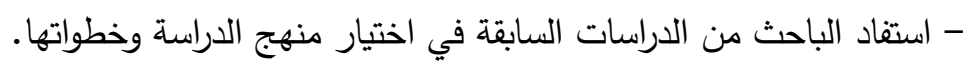

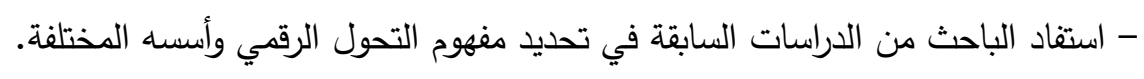

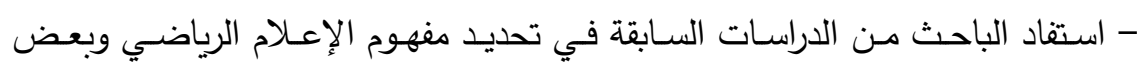

$$
\text { التحديات التي تواجهه. }
$$

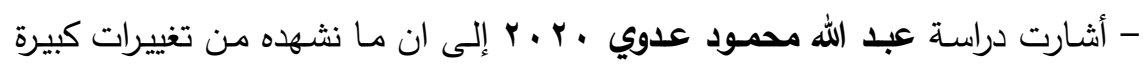

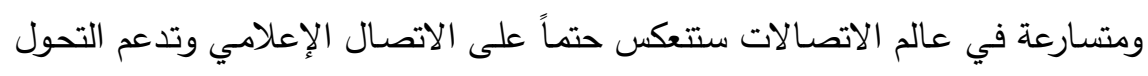

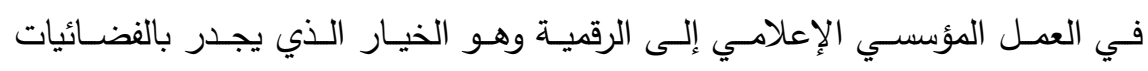
والإذاعات البحث فيه لمواكبة التطورات الحديثة.

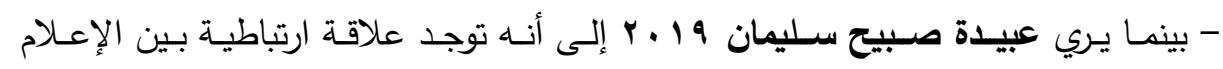

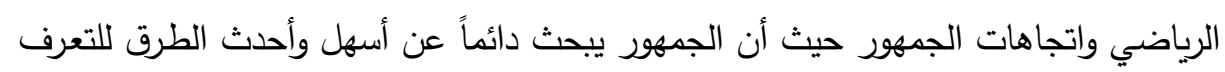

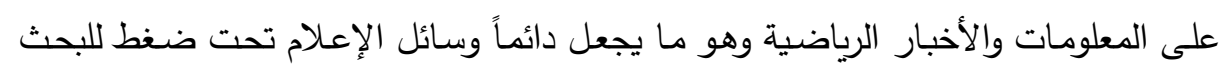
عن كل ما هو جديد في تكنولوجيا الإعلام والتحول الرقمي.

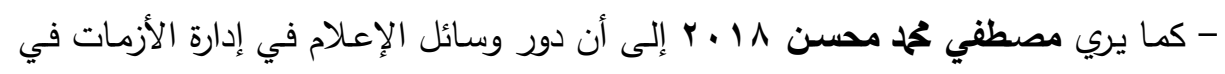
الأندية الرياضية من وجهة نظر المدربين متوسطة الجودة ووجود فروق ذات دات دلالة إحصائية

بين أفراد مجتمع البحث حول دور وسائل الإعلام في إدارة الأزمات في الأندية الرياضية.

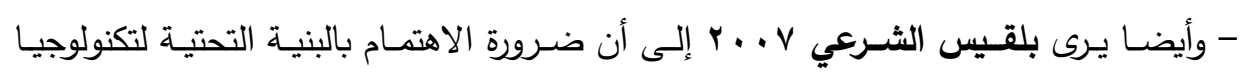

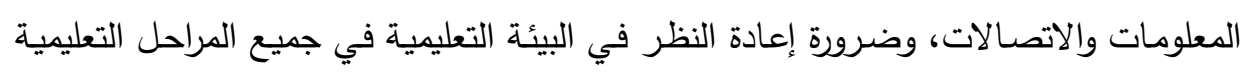

$$
\text { حتى تتماشى ومتطلبات التكنولوجيا الحديثة. }
$$

Elliot Tiffany and Kay, Marianne and و بالإثارة إلى دراسة كل من التطات Lahtinen, M.and Weaver, B ودراسلى تحديات التحول الرقمي وقد أثارت الدراسات لوجود ثلاث طرق موازية لتصميم محتوى تعليمي إعلامي لمواجهة التحول

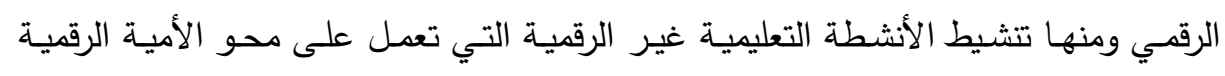
وتوفير الفرص الرقمية التي تعزز الممارسات في الفصول الدراسية التقليدية. 


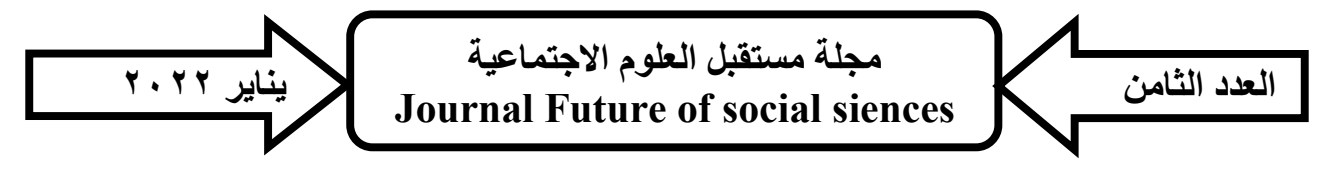

إجراءات البحث:

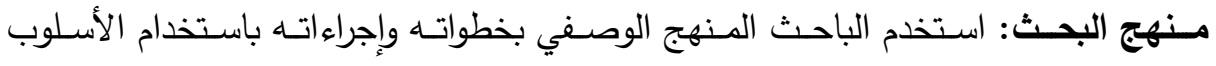
المسحي، نظراً لملائمته لطبيعة عينة البحث.

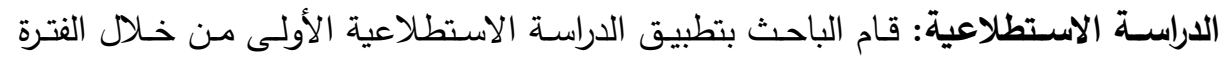

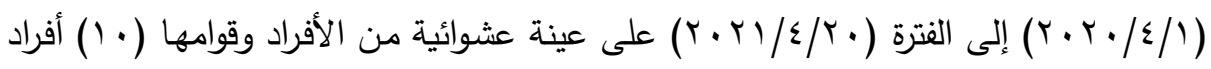
خارج عينة البحث الأساسية بهدف: • التأكد من وضوح وفهم العينة لعبارات الاستبيان. - توضيح طريقة الإجابة على عبارات الاستبيان.

الاراسـة الأساسية:

قام الباحث بتطبيق الدراسة الأساسية بعد حساب المعاملات العلمية لمقياسي البحث من خلال

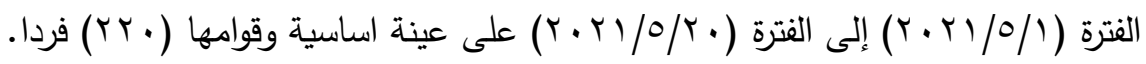
أسلوب المعالجة الإحصائية للبيانات:

تم تحليل البيانات المستخلصة من هذا البحث وفقاً للأساليب الإحصائية التالية: - معامل الارتباط. - النسبة المئوية. - الأهمية النسبية. r s مجتمع وعينة البحث:

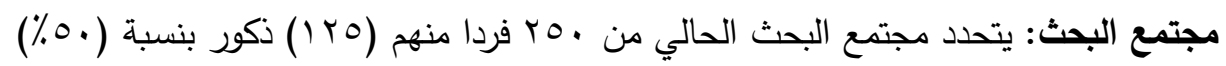

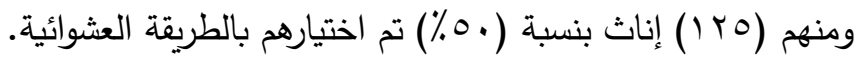

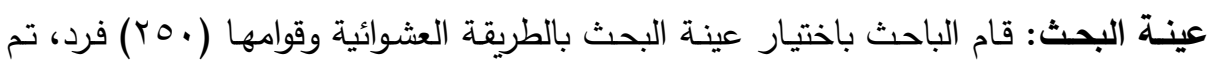

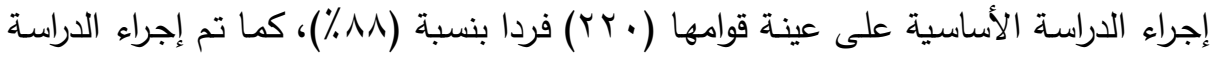

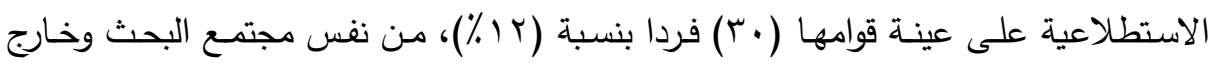
العينة الاساسية. 


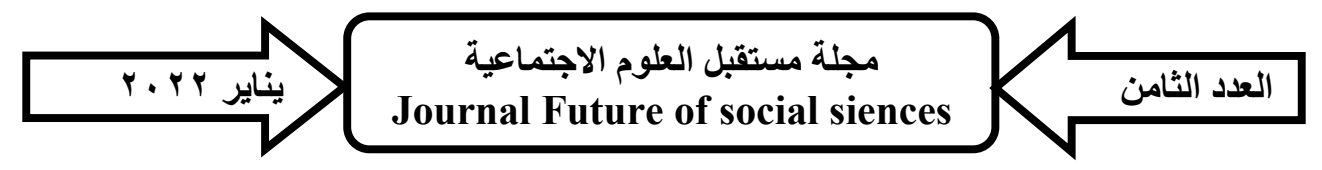

جدول (1) خصائص عينة البحث

\begin{tabular}{|c|c|c|c|c|c|}
\hline الاجمالي & النسبة & عدد الاناث & النسبة & الذكور & العدد النوع \\
\hline 250 & $50 \%$ & 125 & $50 \%$ & 125 & \\
\hline
\end{tabular}

جدول (2) توصيف عينة البحث

\begin{tabular}{|c|c|c|}
\hline العينة الاستطلاعية & العينة الاساسية & العينة الكلية \\
\hline$r$. & Kr. & ro. \\
\hline
\end{tabular}

شروط اختيار العينة:

راع الباحث في اختيار العينة ما يلي:

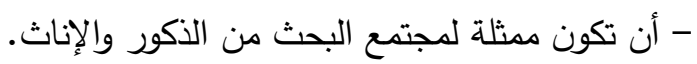

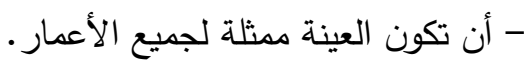

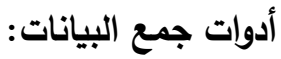
استخدم الباحث في جمع البيانات: - - البيات - مقابلات متعمقة.

حيث قام الباحث بإجراء مقابلات متعمقة مع (خمسة) من الخبراء في مجال الإعلام الرياضي

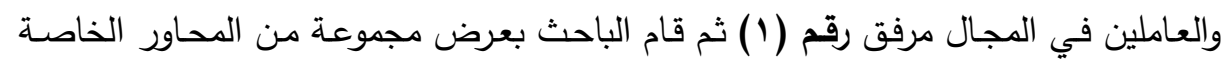

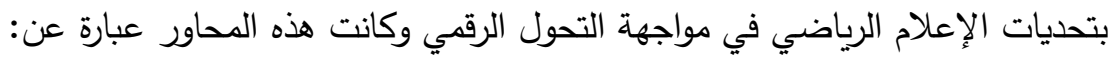
1- تأثير التحول الرقمي على أداء العاملين في مجال الإعلافيلام الرياضي. r- التحول الرقمي سبب في إنهاء خدمة كثير من العاملين في الإعلام الرياضي.

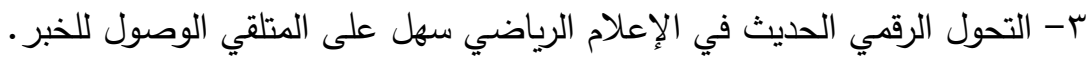

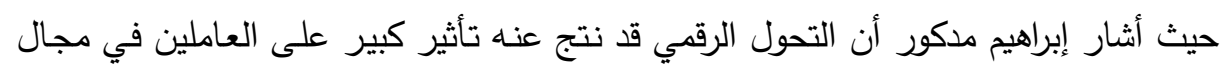

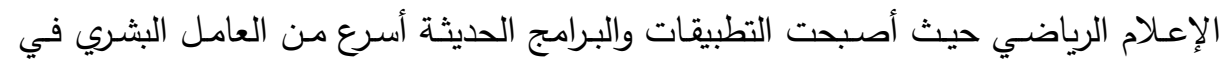

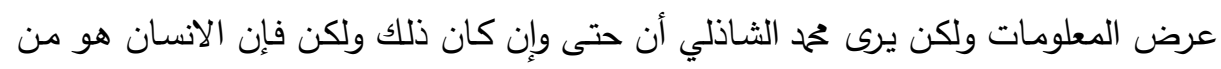

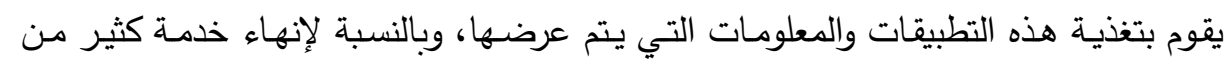

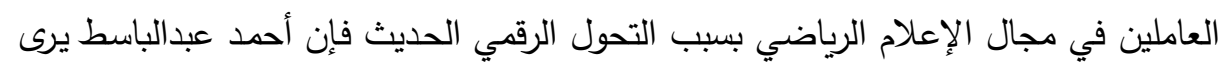

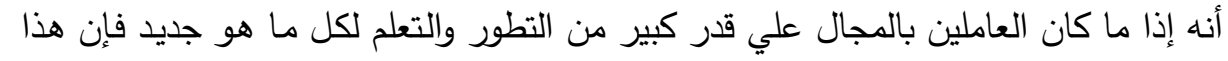

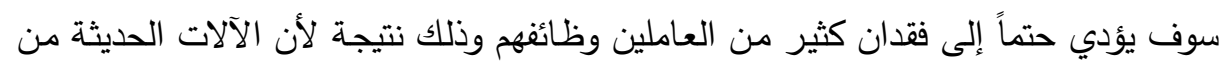

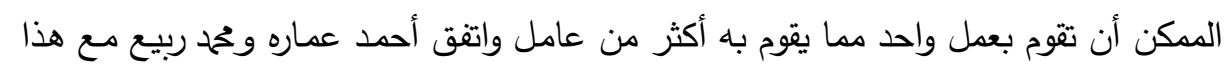




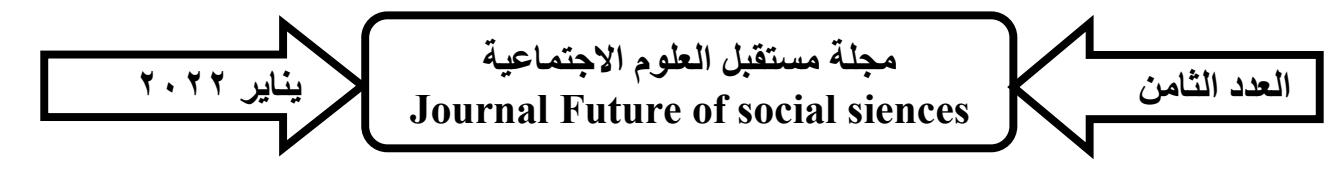

الرأي في حين أن ححم الثـاذلي قد رأى أن المؤسسات الإعلامية الرياضية في مصر تعتمد بشكل أكبر علي العنصر البشري، أما عن أن التحول الرقمي الحديث في مصر قد سهل علي المتلقي الوصول للمعلومة فإن إبراهيم مدكور يرى أنه هناك عدة نوافذ إعلامية تقدم المعلومـة الرياضية والخبر للمتلقي ولكن بعد تجربة استخدام التحول الرقمي في عرض الأخبار فإنـه قد سهل هذه العملية بشكل كبير وقد اتفق معه أحمد عبد الباسط حيث أنه ذكر أن المتلقي من الممكن أن يحصل على أحدث الأخبار بنقرة زر واحدة بدون مجهود وقد عارضهم الرأي محمد ربيع حيث أنه يرى أن الوصول للمعلومة (الموثوقة) يجب أن يكون عن طريق شخص وليس تطبيق أو آلة. - استمارة استبيان “اعداد الباحث". - خطوات بناء استمارة استبيان “اعداد الباحث": 1 - مراجعـة الأطـر النظريـة والدراسـات السـابقة المرتبطـة والمشـابهة بتحديات الإعـلام

$$
\text { الرياضي في مواجهة التحول الرقمي الحديث. }
$$

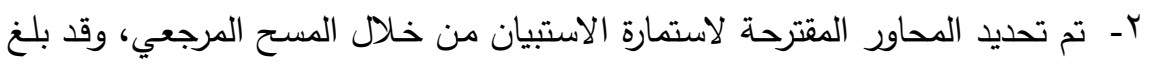

$$
\text { عددها سبعة محاور وهي: }
$$

(ثقافة التحول الرقمي - ثقافـة الإعلام الرياضـي - المتطلبات البثـرية - المتطلبات التقنية - تقييم المتلقي - تقييم العاملين - معوقات التحول الرقمي) تحديد المفهوم النظري الإجرائي لمحاور استمارة الاستبيان المقترح: قام الباحث بوضـع تعريفات إجرائية للمحاور المقترحة استمارة الاستبيان، تمهيداً لعرضها على السـادة الخبراء والذين بلـغ عددهم (0) من الأساتذة المتخصصين في الإعـلام

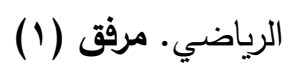

عرض المحاور المقترحة على السادة الخبراء: قام الباحث بإعداد استمارة استطلاع رأى تضـم سبعة محاور ومفهومهم الإجرائي

$$
\text { وذلك لعرضها على الخبراء. مرفق رقم (r) }
$$


جدول (3) رأى السـادة الخبراء في مدى مناسبة المحاور المقترحة لاستمارة الاستبيان

\begin{tabular}{|c|c|c|c|}
\hline$\% 1 \cdots$ & 1. & ثقافة التحول الرقمي & 1 \\
\hline$\%{ }^{\Gamma} \cdot$ & $r$ & المنطلبات البشرية & $r$ \\
\hline$\% 1 \ldots$ & 1 . & ثقافة الاعلام الرياضي & $r$ \\
\hline$\% 1 \ldots$ & 1 . & تقييم المتلقي & $\varepsilon$ \\
\hline$\% \varepsilon$ & $\varepsilon$ & المتطلبات التقنية & 0 \\
\hline$\%$. & $\Lambda$ & تقييم العاملين & 7 \\
\hline$\% 1 \ldots$ & 1. & معوقات التحول الرقمي & $v$ \\
\hline
\end{tabular}

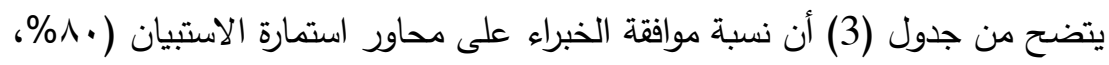

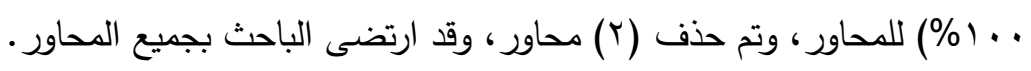
اقتراح عبارات لكل محور من محاور استمارة الاستبيان في ضوء الفهم والتحليل النظري الخاص لكل محور:

قام الباحث بصياغة عبارات المقياس في ضوء الفهم والتحليل النظري الخاص لكل

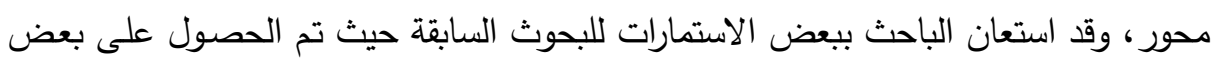

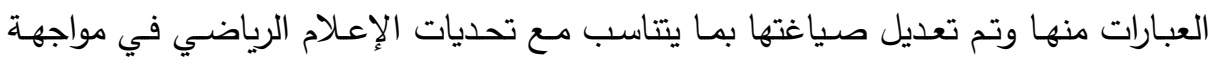

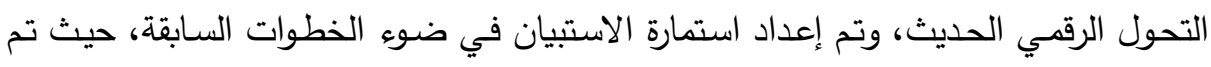

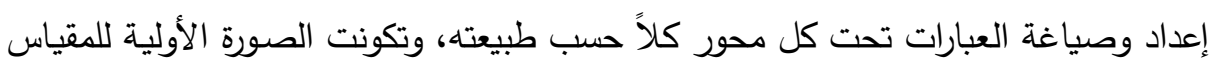
من (آ (§) عبارة.

وقد راعى الباحث في صياغة العبارات ما يلي: - أن تكون العبارات واضحة ومفهومة. - ألا توحي العباغة العبارة بنوع الاستجابـة.

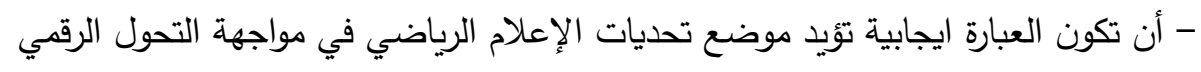

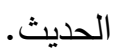
- ألا تثتمل العبارة على أكثر من معنى. 


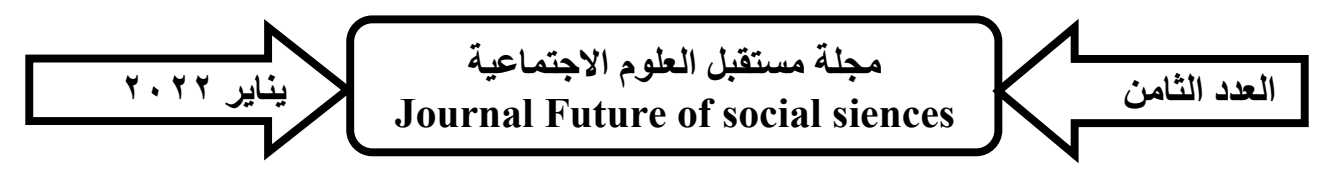

عرض العبارات الخاصـة لكل محـور على السـادة الخبراء للتحقق مـن الصدق المنطقي لملائمة العبارات المقترحة لكل محور:

قام الباحث بعرض المقياس في صورته الأولية على نفس عينة الخبراء التي سبق لعقدر:

$$
\text { ذكرها، وذلك بهدف التعرف على: }
$$

- مدى سلامة صياغة العبارات المقترحة. - حذف أو تعديل أو إضافة عبارات أخرى. - مدى مناسبة العبارات بكل محور "انتماء العبارة للمحور ".

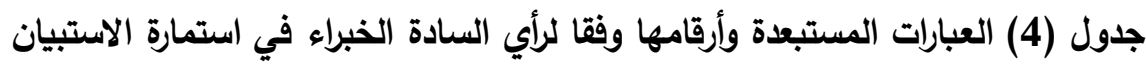

\begin{tabular}{|c|c|c|c|}
\hline \multicolumn{2}{|l|}{ العبارات المستبعدة } & \multirow{2}{*}{ 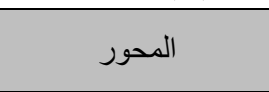 } & \multirow[b]{2}{*}{ s } \\
\hline العبارة & الرقث & & \\
\hline يعتبر التحول الرقمي نجاح في منظومة الاعلام & r & \multirow{2}{*}{ ثقافة التحول الرقمي } & \multirow{2}{*}{1} \\
\hline يعتبر الاعلام الرياضي هادف باستخدام التحول الرقمي & 1. & & \\
\hline هل يوجد علاقه بين الإعلام الرياضي و الإعلام العام & o & ثقافة الإعلام الرياضي & r \\
\hline ما هو فريقاك المفضل & o & \multirow[b]{2}{*}{ تقتييم المتلقي } & \multirow{2}{*}{ r } \\
\hline ما نوع رياضتلك المفضلة & $\Lambda$ & & \\
\hline هل التقنيات الحديثة مفيدة للعاملين في الاعلام الرياضي & 1 & تقييم العاملين & $\varepsilon$ \\
\hline هل هناك ما يعيق عمل النحول الرقمي في المؤسسات الإعلامية & r & \multirow{2}{*}{ معوقات التحول الرقمي } & \multirow{2}{*}{0} \\
\hline هل هناك ما منع استخذام تقنيات حديثة في الدوري المصري & $\mathrm{v}$ & & \\
\hline
\end{tabular}

يتضح من الجدول (4) أن عدد العبارات الدستبعدة من المحور الأول (ثقافة التحول

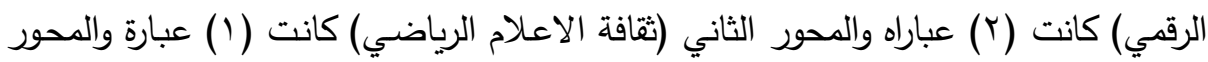

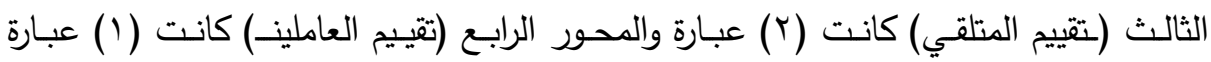

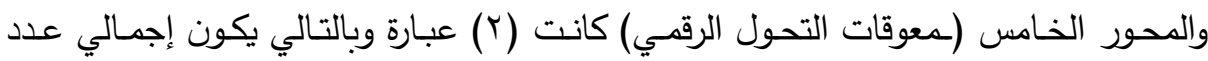

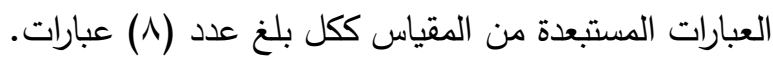

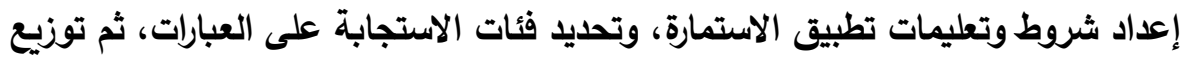

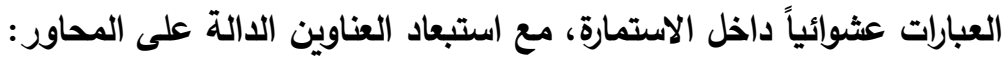

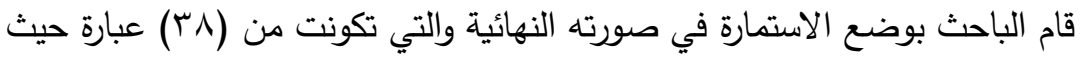

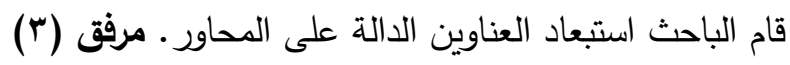




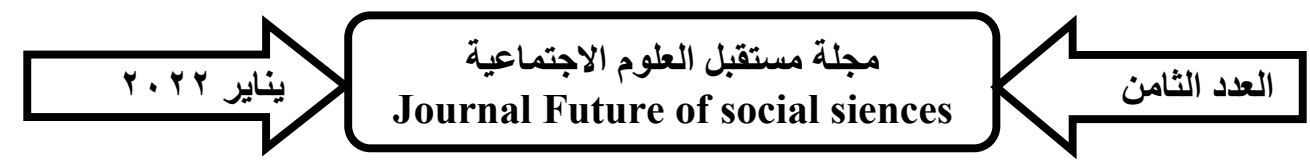

جدول (5) معامل الارتباط بين درجة عبارات المحور الاول والدرجة الكلية للمحور الأول ثقافة التحول الرقمي ن= • بـ

\begin{tabular}{|c|c|c|}
\hline الارتباط & 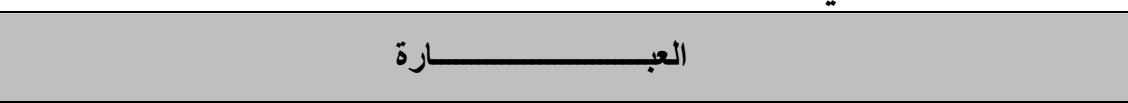 & e \\
\hline$* . . \wedge \vee q$ & هل لديك ادر الك بماهية أنو اع التحول الرقمى & 1 \\
\hline$* . .10$ & هل تري ظهور واضح لاستخدام التحول الرقمي في وسائل الاعلام الرياضية المختلفة & r \\
\hline$* . .717$ & هل تعنقّد أن التطور التكنولوجي ساعد في عملية اخر اج محتوي اعلامي أسر ع من قبل & r \\
\hline$* ., \vee \wedge q$ & تنقل عن طريق النول التعلام الرياضي الحيثيث قد يساهم في رفع القيمة التسويقية للَبر امج و الدوريات التي & $\varepsilon$ \\
\hline$* . .101$ & الهلت تعتقل أن التطور السريع في تكنولوجيا الاعلام الرياض قد تقضي علي بعض الوظائف في & • \\
\hline$* .7 \varepsilon \cdot$ & هل دخول التحول الرقمي في الاعلام الرياضي من أسباب زيادة البرامج الرياضية & 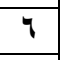 \\
\hline$* . .0 \leqslant r$ & هل التحول الرقمي من أهم أسباب ارتفاع نسب المشاهدة للاعلام الرياضي & $\mathrm{v}$ \\
\hline$* . . \wedge \vee \varepsilon$ & هل الرقمنة الحديثة هدف لكل العاملين في مجال الاعلام الرياضي و المنلقي & $\Lambda$ \\
\hline
\end{tabular}

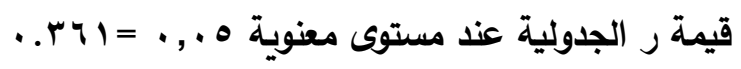

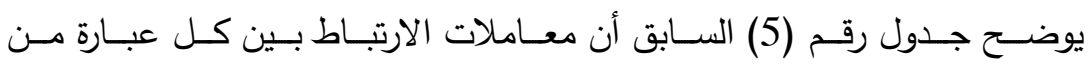

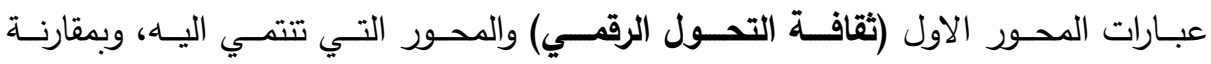

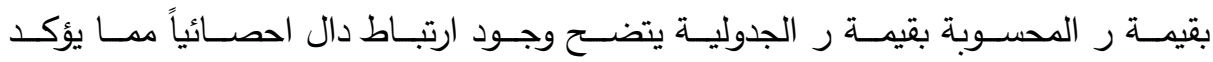

على صدق الاتساق الداخلي لعبارات المحور الاول (ثقافة التحول الرقمي).

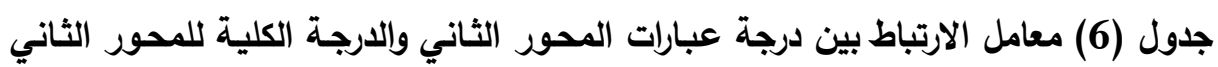

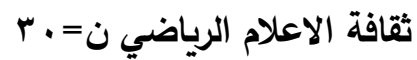

\begin{tabular}{|c|c|c|}
\hline الارتباط & 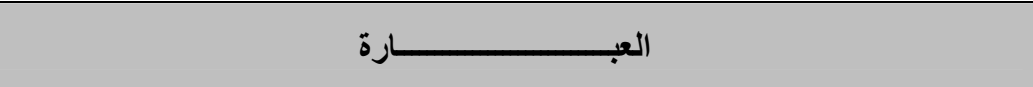 & P \\
\hline *. Vos & هل أنت راضي عن دخول التكنولوجيا الحديثة في الاعلام الرياضي & 1 \\
\hline$* . .011$ & الرقمي يصبح لكليات وأقسام الاعلام والمعاهد المتخصصة دور في الاستفادة بالتحول & r \\
\hline$* . .717$ & 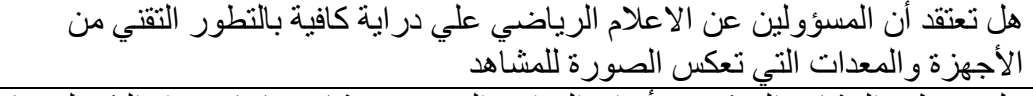 & r \\
\hline$* . \vee \vee 1$ & الحديثة في التحول الرقمي التحكم في أنو اع البرامج التي يريد مشاهدتها باستخدام التكنولوجيا & $\varepsilon$ \\
\hline$* . .70 \mathrm{~V}$ & خاصلة بكل لعبة كل الألعاب و المنافسات المقامة في يوم واحد و عرض بر امج رياضية & 0 \\
\hline$* . .7 \mu$ & هل أنت راضي عن الطريقة التي يتناول بها الإعلام الرياضي الاحداث حاليا & 7 \\
\hline$* . \vee \backslash 11$ & هل يعتبر الاعلام الرياضي نوع من الاعلام الذب ترغب دائما في متابعتّه & $\mathrm{V}$ \\
\hline
\end{tabular}

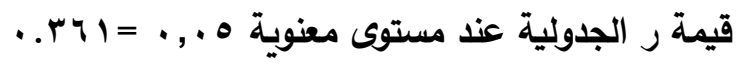




\section{| العدد الثامن}

يوضـح الجدول السابق أن معاملات الارتباط بين كل عبارة من عبارات المحور

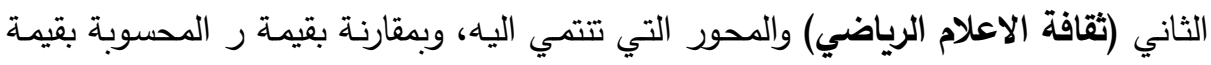

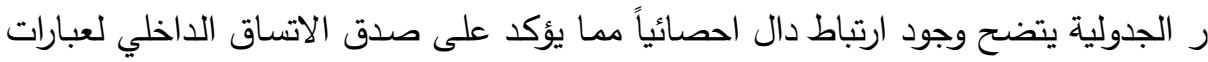

$$
\text { المحور الثاني (ثقافة الإعلام الرياضي). }
$$

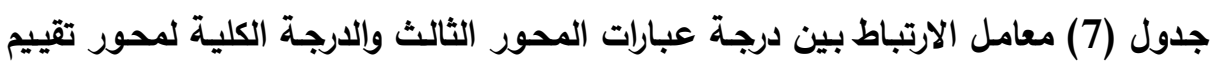

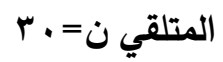

\begin{tabular}{|c|c|c|}
\hline الارتباط & 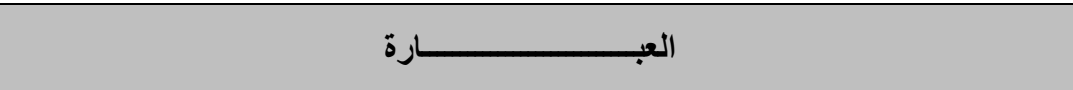 & p \\
\hline$* . \vee \vee 1$ & معدل الوقت الذي تقضيه في مشاهدة البرامج الرياضية يوميا (تقريبا) & 1 \\
\hline$* . .7 \wedge 9$ & معدل الوقت الذي تقضيه في الاستماع إلى الإذاعات الرياضية يو ميا (تقريبا) & $r$ \\
\hline$* . \mathrm{VVV}$ & معدل الوقت الذي تقضيه علي الانترنت يوميا (تقريبا) & $r$ \\
\hline$* .099$ & معدل الوقت الذي تقضيه علي مو اقع التو اصل الاجتماعي كتويتز وفيسبوك يوميا (تقريبا) & $\varepsilon$ \\
\hline$* . \wedge I r$ & معدل الوقت الذي تقضيه في ممارسة الأنشطة الرياضية يوميا (تقريبا) & 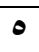 \\
\hline$* .011$ & هل تتابع البر امج الرياضية عن القنوات الرياضية التي تعمل باشتر الك مالي سنويا & 7 \\
\hline$* . \wedge \leqslant \varepsilon$ & هل هناك بر امج رياضية معينة تداوم علي مشاهدتها عن طريق تطبيقات الموبايل & $\mathrm{V}$ \\
\hline$* . \wedge 97$ & هل التحول الرقمي الحديث سبب رئيسي في جعل المشاهد يستمتع أكثر بالبر امج الرياضية & $\Lambda$ \\
\hline
\end{tabular}

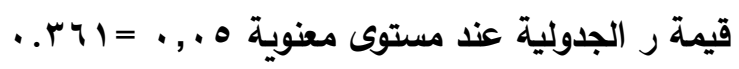

يوضـح الجدول السابق أن معاملات الارتباط بين كل عبدوبه عبارة من عبارات المحور

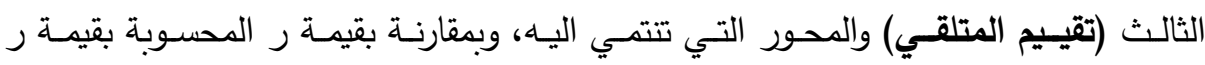

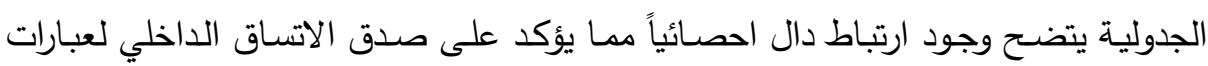

$$
\text { المحور الثالث (تقييم المتلقي). }
$$

\begin{tabular}{|c|c|c|}
\hline 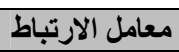 & بـــــارة & $p$ \\
\hline$* . . \vee 97$ & ما العو امل التي أدت إلى استخدام الاتجاه نحو التحول الرقمي في العلام الرياضي المصري & 1 \\
\hline$* .749$ & ما أسباب قلذة اهتمام وسائل الاعلام الرياضي المصري بتكنولوجيا التحول الرقمي & $r$ \\
\hline$* . \wedge \leqslant 7$ & الرقا أهم منطلبات تطور وسائل الاعلام الرياضي المصري لما وصلت له تكنولوجيا التحول & $r$ \\
\hline$* . . \vee \vee \wedge$ & ما أهم مشكلات وتحديات الاستعانة بأدوات التحول الرقمي في وسائل الاعلام الرياضي & $\varepsilon$ \\
\hline$* .719$ & ما أسباب التحول لوسائل الاعلام الذكية عن طريق التحول الرقمي & 0 \\
\hline$* . \vee \wedge \varepsilon$ & كيف نحمي تجربة استخدام التحول الرقمي قيميا & 9 \\
\hline$* . .10$ & ما درجة تأثتير التحول الرقمي علي قدرات وسائل الاعلام الرياضي في المستقبل في رأيك & $\mathrm{v}$ \\
\hline
\end{tabular}

جدول (8) معامل الارتباط بين درجة عبارات المحور الرابع والدرجة الكلية للمحور تقييم

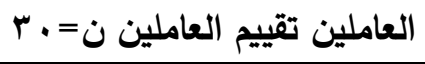

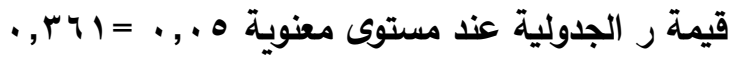




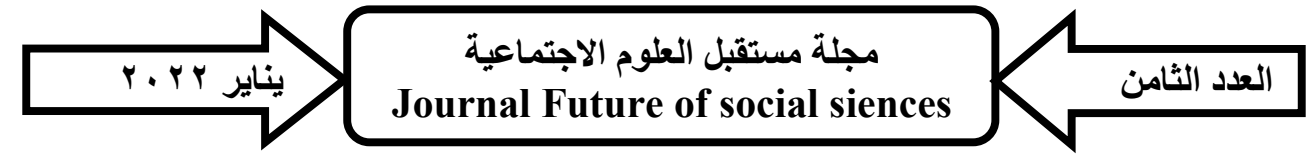

يوضـح الجدول السابق أن معاملات الارتباط بين كل عبارة من عبارات المحور

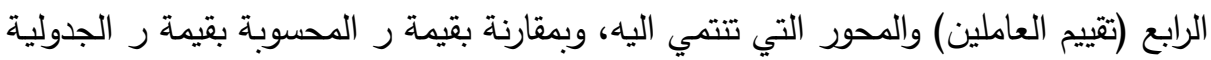

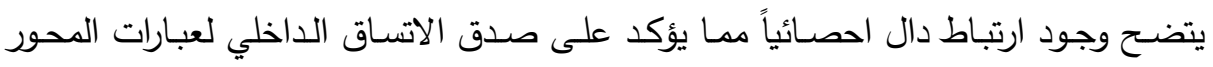

الرابع (تقييم العاملين)

جدول (9) معامـل الارتبـاط بين درجـة عبـارات المحور الخـامس والدرجـة الكليـة للمحور

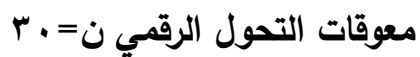

\begin{tabular}{|c|c|c|}
\hline 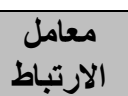 & 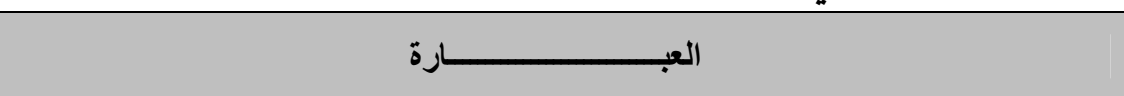 & $p$ \\
\hline$* . \wedge T r$ & هل تعتقد أن الاعلام الرياضي في مصر مو اكب للتحول الرقمي الحديث في الفترة الحالية & 1 \\
\hline$* . V I T$ & هل التكنولوجيا المستخدمة في الاعلام الرياضي مناسبة لتطلعاتك & r \\
\hline$* .0 \vee 9$ & هل دخول التحول الرقمي في الاعلام الرياضي من أسباب زيادة البر امج الرياضية & $\mu$ \\
\hline$* . \vee 10$ & في التحول الرقمي المشاهد التحكم في أنواع البر امج التي يريد مشاهدتها باستخدام التكنولوجيا الحديثة & $\varepsilon$ \\
\hline *. .Tr & هلّ تتابع البر امج الرياضية عن طريق الموبايل & - \\
\hline$* . . \vee 0 \leqslant$ & راضي عنهاك عدد كاف من الأدوات الحديثة المستخدمة في البر امج التليفزيونية الرياضية أنت & 7 \\
\hline$* . .71$. & هل نقل الفاعليات و الأحداث الرياضية أصبح تقنيا أفضل بعد دخول التحول الرقمي المجال & $\mathrm{V}$ \\
\hline$* . \wedge \leqslant 0$ & هل يعتبر التحول الرقمي الحديث هم من أنجح الاعلام علي مر العصور & $\Lambda$ \\
\hline
\end{tabular}

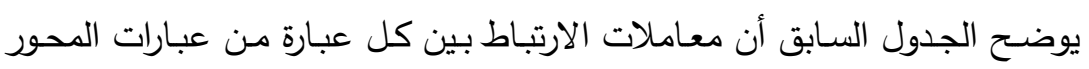

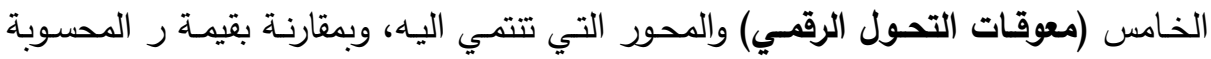

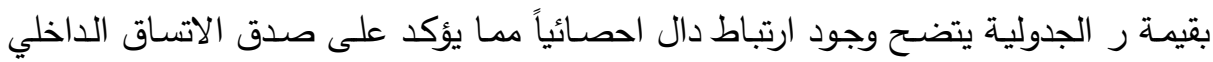
لعبارات المحور الخامس (معوقات التحول الرقمي)

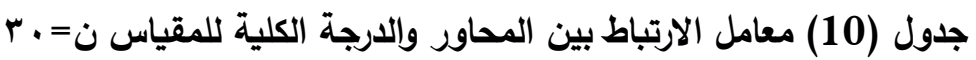

\begin{tabular}{|c|c|c|}
\hline الارتباط & المحـــــــــــاور & 5 \\
\hline 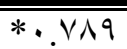 & ثقافة التحول الرقمى & 1 \\
\hline$* . V \leqslant 1$ & ثقافة الاعلام الرياضي & $\bar{r}$ \\
\hline$* . .7 \wedge \varepsilon$ & تقييم المتلقي & $r$ \\
\hline$* . . v 11$ & تقبيم العاملين & $\varepsilon$ \\
\hline$* .749$ & معوقات التحول الرقمي & 0 \\
\hline
\end{tabular}

قيمة ر الجدولية عند مستوى معنوية ه. ,. =. آسب, . 


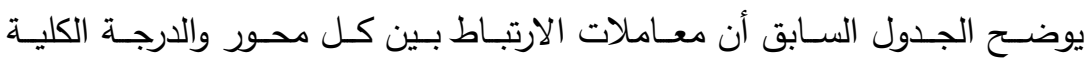
للاستمارة، وبمقارنـة بقيمة ر المحسوبة بقيمة ر الجدولية يتضـح وجود ارتباط دال احصـائياً مما يؤكد على صدق الاتساق الداخلي لمحاور المقياس. ثبات المقياس:

قام الباحث بتطبيق المقياس على عينة التقنين (العينة الاستطلاعية) وقوامها (•r) فرد من خارج عينة البحث الأساسية، وتم حساب معامل الفاكورنباخ بطريقة التجزئة لحساب الثبات:

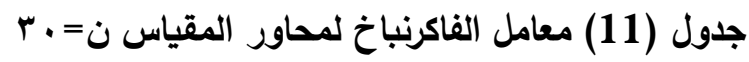

\begin{tabular}{|c|c|c|}
\hline معامل الفاكرنباخ & المحـــــــاور & s \\
\hline$* . .709$ & ثقافة التحول الرقمي & 1 \\
\hline$* . \vee \vee \wedge 0$ & ثقافة الاعلام الرياضي & $r$ \\
\hline$* . .71 \mathrm{r}$ & تقييم المتلقي & $r$ \\
\hline$* . .7 \mu \Lambda$ & تقييم العاملين & $\varepsilon$ \\
\hline$* . .707$ & معوقات التحول الرقمي & 0 \\
\hline
\end{tabular}

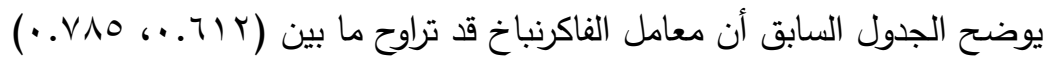

وهي معاملات دال احصائياً مما يؤكد على ثبات محاور الاستمارة.

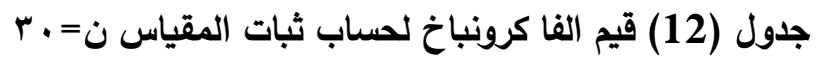

\begin{tabular}{|c|c|}
\hline القيمة & البيان \\
\hline$* . \wedge \vee 0$ & معامل الارتباط بين الجزئين \\
\hline$* .9 r \mu$ & معامل جتمان \\
\hline$* . \wedge \ldots$ & معامل الفا للجزء الاول \\
\hline$\because \wedge \leqslant 0$ & معامل الفا للجزء الثاني \\
\hline
\end{tabular}

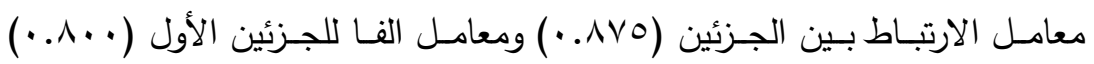

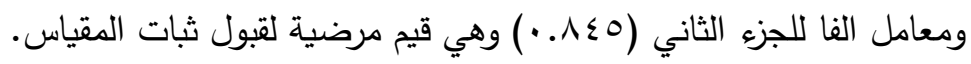




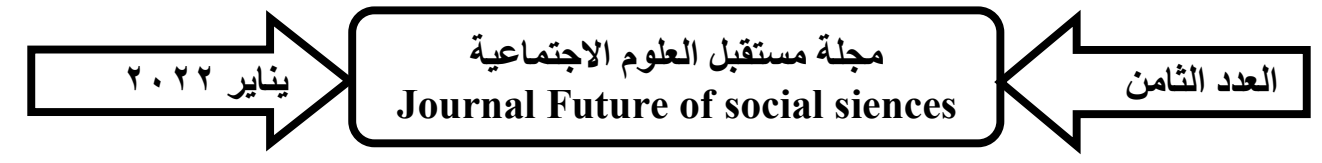

عزض وتفسير ومناقشة النتائج:

عرض النتائج:

عرض النتائج الخاصة باستمارة الاستبيان:

جدول (13) الأهمية النسبية والتكرارات والنسبة المئوية لإجابات عينة البحث على على المحور

rr. $=\dot{0}$

الاول ثقافة التحول الرقمي (13 الاهيه

\begin{tabular}{|c|c|c|c|c|c|c|c|c|c|c|c|c|}
\hline \multirow{2}{*}{ sis } & \multirow{2}{*}{ الالنمبية } & \multirow{2}{*}{ التقليرى المن } & \multicolumn{2}{|c|}{ أبداً } & \multicolumn{2}{|c|}{ نادراً } & \multicolumn{2}{|c|}{ أحياتاً } & \multicolumn{2}{|c|}{ غالباً } & \multirow{2}{*}{ العبــــــــــــة } & \multirow[b]{2}{*}{ p } \\
\hline & & & $\%$ & s & $\%$ & 5 & $\%$ & S & $\%$ & S & & \\
\hline זr. & qr.vo & $\leq 0 . .$. & $\cdot \lambda r$ & $1 .$. & $1.7 \mathrm{~V}$ & r... & 19.18 & $r$ r... & VA.rr & १ะ... & الرقل لديك ادر الك بماهية أنواع التحول & 1 \\
\hline ITY.VT & $q \cdot r_{1}$ & $\varepsilon r r .$. & $\cdot \lambda r$ & $1 .$. & ๕.IV & $0 .$. & YA.rT & $r \varepsilon .$. & $77.7 \mathrm{~V}$ & $\wedge \cdot .$. & 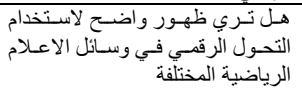 & $r$ \\
\hline 171.95 & 91 . & $\varepsilon r \Lambda_{.}$. & $1.7 \mathrm{~V}$ & r... & $0 . \Lambda r$ & $v_{.} .$. & IN.Tr & rr.. & $V \leqslant . \mid V$ & $\wedge 9 .$. & 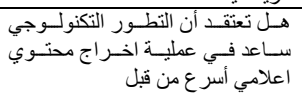 & $r$ \\
\hline$\leq 7 . V T$ & vq.rی & rی1... & ג.r & $1 \cdot$. & $11.7 \mathrm{~V}$ & $1 \leqslant .$. & $r \varepsilon .1 V$ & $\{1 .$. & $\leq 0 . \wedge r$ & $00 . .$. & 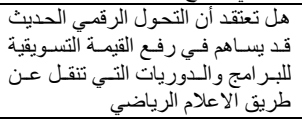 & $\varepsilon$ \\
\hline$r \mid \leq . \wedge V$ & 94.97 & $\leq 01 \ldots$ & $1.7 V$ & $r_{.} . \cdot$ & $r . r r$ & $\varepsilon \ldots$ & Ir.o. & $10 .$. & Ar.o. & $99 .$. & 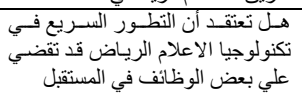 & 0 \\
\hline KO $r_{0} \leqslant V$ & $19.1 \mathrm{~V}$ & $\varepsilon r \Lambda_{.}$. & r.o. & $r .$. & ¿.IV & $0 .$. & rr.o. & rז... & To.人r & va... & 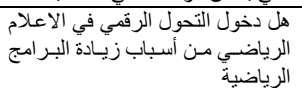 & 7 \\
\hline $1 \leqslant 9.7 V$ & 19. $\vee 9$ & $\varepsilon r 1 .$. & r. & $\varepsilon .$. & $7.7 \mathrm{~V}$ & $\wedge_{.} .$. & IV.o. & $r 1 .$. & VT.O. & $\Delta v_{.}$. & 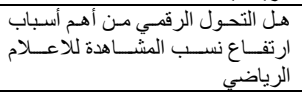 & V \\
\hline AT.TV & so... & $\varepsilon \cdot \wedge_{.}$. & זr. & $\varepsilon .$. & $0 .$. & $7 .$. & $\varepsilon, \ldots$ & $\varepsilon \wedge .$. & $01.7 \mathrm{~V}$ & $\pi$ r... & 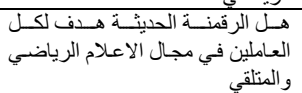 & $\lambda$ \\
\hline
\end{tabular}

يتضح من جدول (14) وجود فروق دالة احصائياً بين استجابات عينة البحث على عبارات

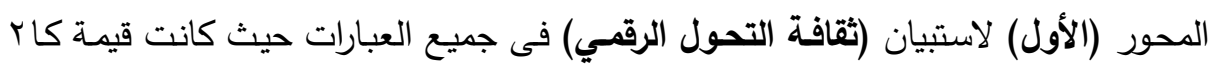

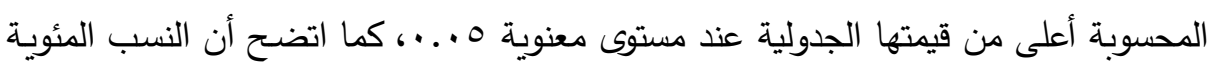

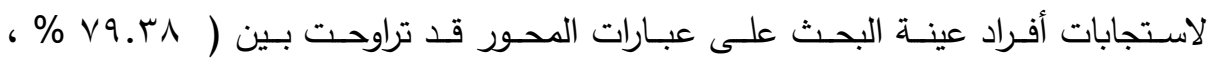
.$(\% 9 r . v 0$ 


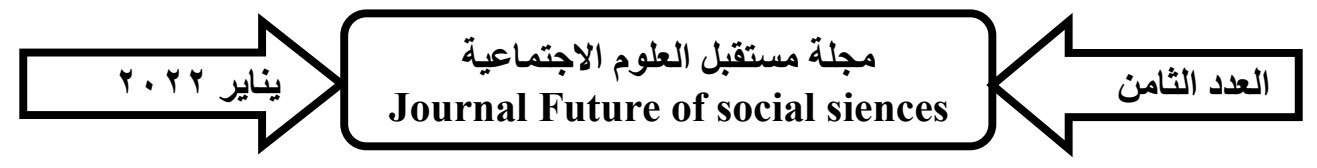

جدول (14) الأهمية النسبية والتكرارات والنسبة المئوية لإجابات عينة البحث على المحور

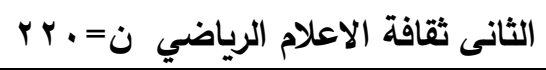

\begin{tabular}{|c|c|c|c|c|c|c|c|c|c|c|c|c|}
\hline \multirow{2}{*}{ كا' } & \multirow{2}{*}{ الالاهبية } & \multirow{2}{*}{ التقايرى } & \multicolumn{2}{|c|}{ أبداً } & \multicolumn{2}{|c|}{ نادرا } & \multicolumn{2}{|c|}{ أحياتًا } & \multicolumn{2}{|c|}{ غالباً } & \multirow{2}{*}{ 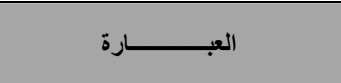 } & \multirow[b]{2}{*}{ p } \\
\hline & & & $\%$ & ك & $\%$ & ك & $\%$ & ك & $\%$ & ك & & \\
\hline lor.y. & $9 . .7 \pi$ & $\varepsilon r o,$. & $1.7 \mathrm{~V}$ & r... & $7 . T \mathrm{~V}$ & $\wedge_{.}$. & 19.18 & $r$ r... & vr.o. & $\Delta v_{.}$. & 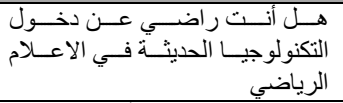 & 1 \\
\hline or.r. & $\lambda \cdot . T$ & rAv... & ¿.IV & $0 .$. & $1 \leqslant .1 \mathrm{~V}$ & IV... & M. $7 \mathrm{~V}$ & $\varepsilon \varepsilon$. & $\leqslant 0, \ldots$ & $0 \varepsilon_{.}$. & 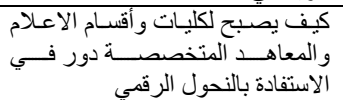 & r \\
\hline $\mid \varepsilon 1.1 T$ & 19.01 & $\varepsilon r \cdot .$. & $1 . v$. & r... & Q.५. & $11 .$. & |A.r. & rr... & $\vee \cdot . \wedge$. & 10... & 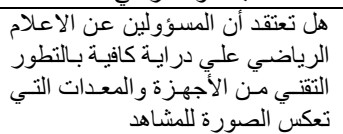 & $r$ \\
\hline $1 \cdot \lambda . \wedge v$ & AY.rq & $\varepsilon 19 .$. & r.o. & $r .$. & $1 \cdot \ldots$ & Ir... & rT.r. & $r_{\text {A.. }}$. & T\&.Y. & vv... & 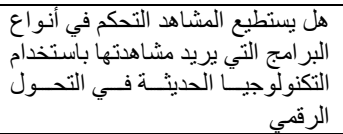 & $\varepsilon$ \\
\hline V৭.४ & $\Lambda \varepsilon .0 \wedge$ & $\varepsilon \cdot \uparrow,$. & r.o. & $r .$. & A.r. & $1, \ldots$ & rY.o. & $\leqslant 0 .$. & $01 . v$. & $\pi . .$. & 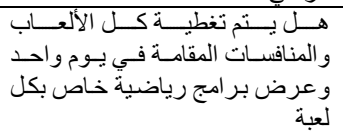 & 0 \\
\hline 1.9 .4$. & $\Delta v_{.} \cdot \Lambda$ & $\varepsilon \mid \wedge_{.} \cdot$ & $\varepsilon . \varphi$. & $0 .$. & v.o. & $9 .$. & $r \leq .,$. & $r q .$. & $T \leqslant . Y$. & vv... & يتناول بها الاعلام الرياضي الطريقـة التــي & 7 \\
\hline $11.0 \%$ & $M, . r T$ & $\varepsilon r \varepsilon .$. & $\cdot \wedge$. & $1 .$. & $\varepsilon .{ }_{\text {. }}$ & $0 .$. & ro.s. & $\varepsilon r .$. & 09.4. & $v_{1} .$. & الاعلام الذي تر تلام الريائما في منابعته من & v \\
\hline
\end{tabular}

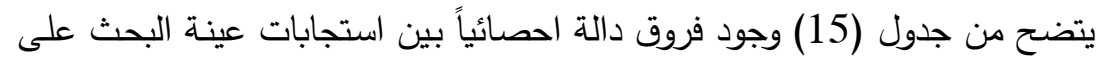

عبارات المحور (الثاني) لاستبيان (ثقافة الاعلام الرياضي) فى جميع العبارات حيث كانت

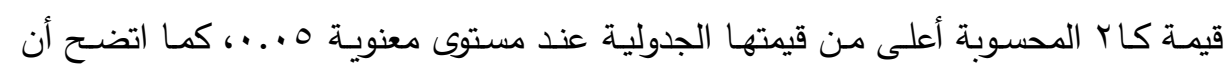

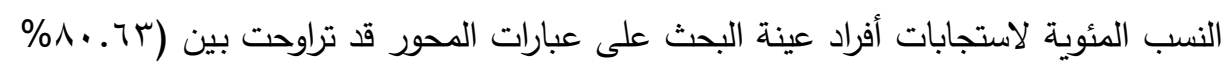

$$
(\% 9 \cdot .74 \text {. }
$$

جدول (15) الأهمية النسبية والتكرارات والنسبة المئوية لإجابات عينة البحث على المحور

\begin{tabular}{|c|c|c|c|c|c|c|c|c|c|c|c|c|}
\hline \multirow[t]{2}{*}{ ris } & \multirow{2}{*}{ الاهمبية } & \multirow{2}{*}{ التقديرى الوزن } & \multicolumn{2}{|c|}{ أبداً } & \multicolumn{2}{|c|}{ نادرأ } & \multicolumn{2}{|c|}{ أحياتاً } & \multicolumn{2}{|c|}{ غالباً } & \multirow[b]{2}{*}{ 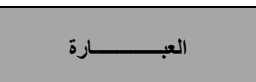 } & \multirow[b]{2}{*}{ b } \\
\hline & & & $\%$ & ك & $\%$ & S & $\%$ & s & $\%$ & ك & & \\
\hline IVI.or & 91.11 & $\varepsilon \leqslant 1 .$. & $\cdot \wedge$. & $1 \ldots$ & $7 . V$. & $\wedge .$. & 17.8. & $r . .$. & vo.A. & $91 .$. & 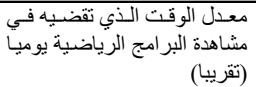 & 1 \\
\hline$\wedge \leq . \wedge V$ & $\Lambda \leq .01$ & $\varepsilon .7$. & $0 .$. & ๆ. & $1 . \wedge$. & $1 \pi .$. & ro... & $r . .$. & 09.4. & $v_{1} . .$. & 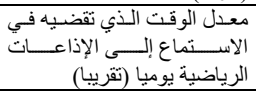 & r \\
\hline QV.TV & ᄉ.. TV & $\leqslant 17 . \ldots$ & r.o. & r... & $\wedge . \Gamma$. & $1 . \cdots$ & rq. . . & ro... & $7 .$. & $V Y .$. & الانترنت يوميا (تقريبا) الوقضيه علي & $r$ \\
\hline$T \leqslant . \leqslant V$ & $\leqslant v .0$. & rrı... & $07 . V$. & $7 \wedge .$. & ir.o. & $10 .$. & $10 .$. & $11 .$. & $10 . \wedge$. & $19 .$. & 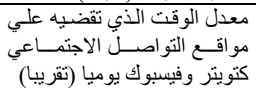 & $\varepsilon$ \\
\hline
\end{tabular}

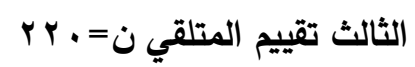




\section{العدد الثامن}

\begin{tabular}{|c|c|c|c|c|c|c|c|c|c|c|c|c|}
\hline \multirow[t]{2}{*}{ S L } & \multirow{2}{*}{ الالنسبية } & \multirow{2}{*}{ التقايرى } & \multicolumn{2}{|c|}{ أبدأ } & \multicolumn{2}{|c|}{ نادراً } & \multicolumn{2}{|c|}{ أحياناً } & \multicolumn{2}{|c|}{ غالباً } & \multirow[b]{2}{*}{ 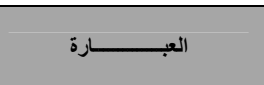 } & \multirow[b]{2}{*}{ P } \\
\hline & & & $\%$ & s & $\%$ & ك & $\%$ & 5 & $\%$ & s & & \\
\hline $104 .$. & $\wedge 9 . \wedge \wedge$ & \& १q.. & $0 .$. & 7. & $0 . \wedge$. & $v_{.}$. & 10.1. & $19 .$. & VT.r. & $\wedge_{.} .$. & 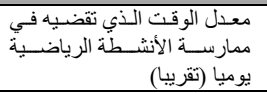 & 0 \\
\hline $110 . r$. & NY.O. & $\varepsilon r \cdot . \cdots$ & $0 .$. & 7.. & $0 .$. & $7 .$. & ro... & $r \cdot .$. & $10 . .$. & $v_{\wedge} . .$. & 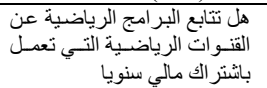 & 7 \\
\hline$\| \wedge . \wedge v$ & $11.0 \leqslant$ & $\leqslant r o .$. & r.o. & $r .$. & $0 . \wedge r$ & $v_{.} .$. & YY.TV & $r_{\text {r. }}$. & $10 . .$. & vı... & 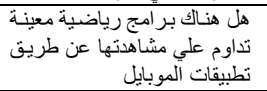 & v \\
\hline $17 \Lambda .,$. & QY.Y & $\leqslant \leqslant 0, \cdots$ & $\cdot \Delta r$ & $1 . \cdots$ & $\cdot \lambda \Gamma$ & $1 \ldots$ & ro... & $r \cdot .$. & Tr.r. & $\wedge_{.} .$. & 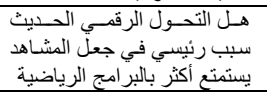 & $\wedge$ \\
\hline
\end{tabular}

يتضح من جدول (16) وجود فروق دالة احصائياً بين استجابات عينة البحث على البى

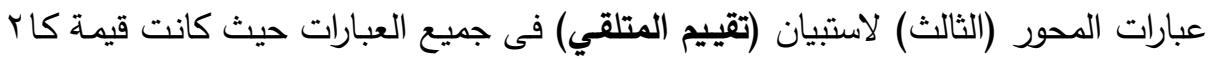

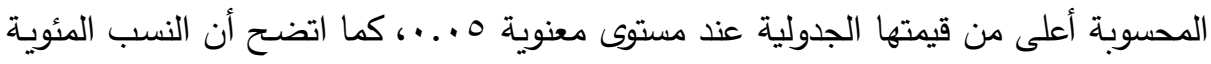

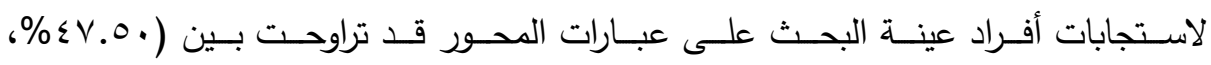
. (\%9r.v)

جدول (16) الأهمية النسبية والتكرارات والنسبة المئوية لإجابات عينة البحث على المحور

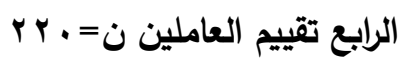

\begin{tabular}{|c|c|c|c|c|c|c|c|c|c|c|c|c|}
\hline \multirow{2}{*}{ كاי } & \multirow{2}{*}{ الاهمبية } & \multirow{2}{*}{ التقليرى } & \multicolumn{2}{|c|}{ أبدأ } & \multicolumn{2}{|c|}{ نادرا } & \multicolumn{2}{|c|}{ أحياناً } & \multicolumn{2}{|c|}{ غالبًا } & \multirow{2}{*}{ العبــــــــــارة } & \multirow[b]{2}{*}{ e } \\
\hline & & & $\%$ & 5 & $\%$ & 5 & $\%$ & s & $\%$ & 5 & & \\
\hline I9Y.AY & 94.14 & $\varepsilon \leqslant v .$. & $\cdot \lambda \mu$ & $1 . \cdots$ & $0 .$. & $7 .$. & $10 .$. & $11_{.}$. & V9.1V & $90 . .$. & 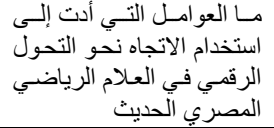 & 1 \\
\hline Wr.or & $1 \Lambda_{.0} .0 \varepsilon$ & $\varepsilon r o, .$. & $\cdot \lambda r$ & $1 \ldots$ & $1 \cdot . \wedge r$ & $1 \% .$. & $r 1 . T V$ & r... & $74.7 \mathrm{~V}$ & $\wedge \cdot .$. & 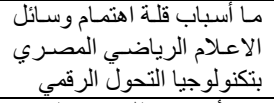 & $r$ \\
\hline $1 \leqslant .94$ & $\mu_{1} \mathrm{v}_{0}$ & $\varepsilon r \uparrow .$. & $0 . \lambda \mu$ & $v .$. & $\varepsilon .1 V$ & $0 .$. & 19.18 & $r r .$. & $v \cdot \wedge r$ & 10... & 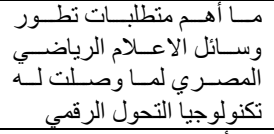 & $r$ \\
\hline $1 \leqslant \Lambda, r$. & $91 . . \varepsilon$ & $\varepsilon r v .$. & $\cdot \lambda r$ & $1 .$. & $0 .$. & 7. & Tr.TT & $r_{.} .$. & $V \cdot . \wedge T$ & $10 . .$. & 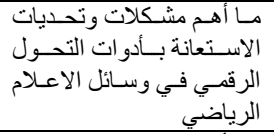 & $\varepsilon$ \\
\hline $1 \leqslant r . \leqslant$. & $q \cdot, r)$ & $\varepsilon r \mu .$. & $\cdot \lambda r$ & $1 .$. & $\Lambda . \mu r$ & $1 \cdots$ & $r \cdot$. & $r \varepsilon \ldots$ & $V \cdot . \wedge T$ & $10 . .$. & 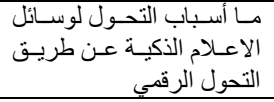 & 0 \\
\hline Tro.TV & $1 \wedge .0 \varepsilon$ & $\varepsilon r o, .$. & $r . \mu \mu$ & $\varepsilon .$. & $7.7 V$ & $\Lambda_{.}$. & rr.o. & $r r_{.}$. & Tr.o. & $11 .$. & التحـــ نحمي تجريمية استخدام & 7 \\
\hline $1 r \cdot . \cdot v$ & 11.97 & $\varepsilon r v .$. & $\varepsilon .1 V$ & $0 .$. & $r . r \mu$ & $\varepsilon$. & ro... & $r \because .$. & TY.O. & 1)... & 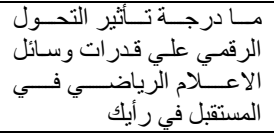 & v \\
\hline
\end{tabular}




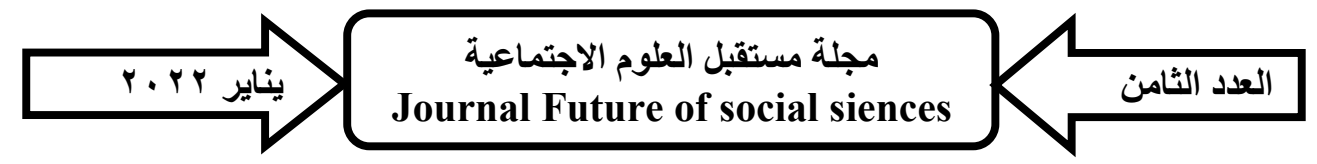

يتضح من جدول (17) وجود فروق دالة احصائياً بين استجابات عينة البحث على البى البح

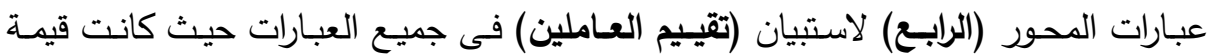

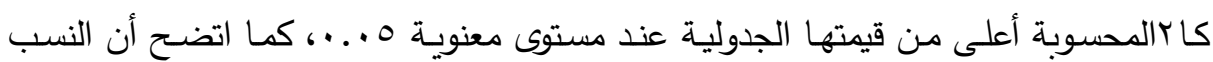

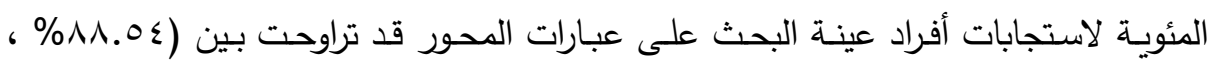

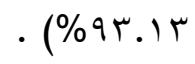
جدول (17) الأهمية النسبية والتكرارات والنسبة المئوية لإجابات عينة البحث على المحور

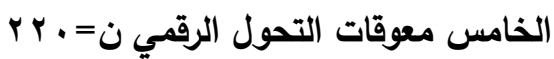

\begin{tabular}{|c|c|c|c|c|c|c|c|c|c|c|c|c|}
\hline \multirow{2}{*}{ Sis } & \multirow{2}{*}{ الاهمبية } & \multirow{2}{*}{ التقديرى } & \multicolumn{2}{|c|}{ أبداً } & \multicolumn{2}{|c|}{ نادراً } & \multicolumn{2}{|c|}{ أحيانًاً } & \multicolumn{2}{|c|}{ غالباً } & \multirow{2}{*}{ 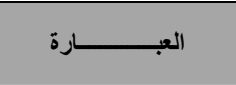 } & \multirow[b]{2}{*}{ p } \\
\hline & & & $\%$ & s & $\%$ & ك & $\%$ & ك & $\%$ & s) & & \\
\hline $1 \leq 7 . \wedge$ & $q \cdot . \wedge r$ & 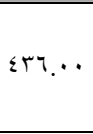 & $\cdot \wedge r$ & $1 . \cdots$ & $0 . \wedge r$ & $v_{.} .$. & r. 0. & $r v . .$. & $v \cdot . \wedge r$ & $10 .$. & 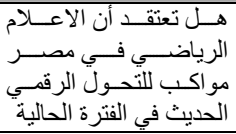 & 1 \\
\hline 79.04 & אז.זה & $\varepsilon \cdots$ & \&.) & $0 . \cdots$ & $11.7 \mathrm{~V}$ & $1 \leq .$. & $r \cdot . \wedge r$ & $r v . .$. & זr.זם & $7 \varepsilon .$. & 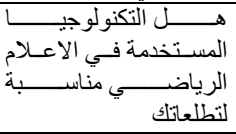 & $r$ \\
\hline r. & $v \varepsilon . \vee q$ & roq... & $11.7 \mathrm{~V}$ & $1 \leq .$. & זיז.דז & rᄉ... & $19.1 \mathrm{~V}$ & r.... & $\leqslant 0 . \wedge r$ & $00 .$. & 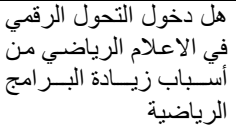 & $r$ \\
\hline Ir.A. & AN. IT & $\varepsilon r r .$. & $0 .$. & 7.. & V.O. & १... & $1 V .0$. & r.... & $v \cdot \ldots$ & $\wedge \varepsilon .$. & 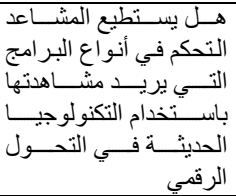 & $\varepsilon$ \\
\hline $1.0 .7 \mathrm{~V}$ & $\lambda V_{.} \cdot \lambda$ & $\varepsilon 1 \wedge .$. & r.o. & $r .$. & $1 \cdot \ldots$ & Ir... & $r \leq .1 V$ & rq... & זיז.זי & $v ч .$. & 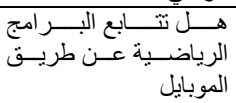 & 0 \\
\hline $1 \leqslant 7 . \leqslant V$ & $9 \cdot .74$ & $\varepsilon r o, .$. & $1.7 \mathrm{~V}$ & $r_{.}$. & $0 .$. & $7 .$. & r. O. & $r v . .$. & $v \cdot . \wedge r$ & $10 .$. & 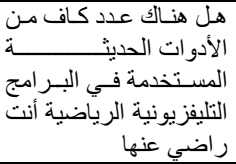 & 7 \\
\hline \&T. & $\leqslant V . r q$ & rYV... & $\varepsilon 9.1 \mathrm{~V}$ & $09 .$. & ro.Ar & r... & $11.7 \mathrm{~V}$ & $1 \leq \ldots$ & אז.זו & $17 .$. & 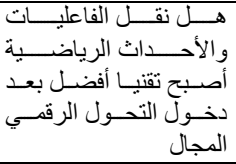 & v \\
\hline Tr. 107 & 11.97 & $\varepsilon r V_{.}$. & $0 . \wedge r$ & $v_{.}$. & $7.7 V$ & $\wedge .$. & זr.זו & $17 . \ldots$ & $V \leq .1 V$ & $19 .$. & 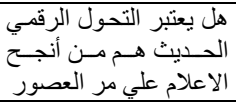 & $\wedge$ \\
\hline
\end{tabular}

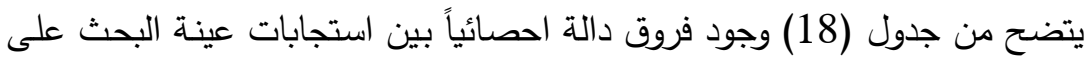

عبارات المحور (الخامس) لاستبيان (معوقات التحول الرقمي) فى جميع العبارات حيث كانت

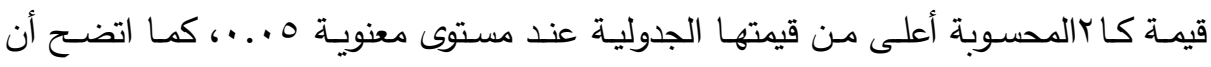




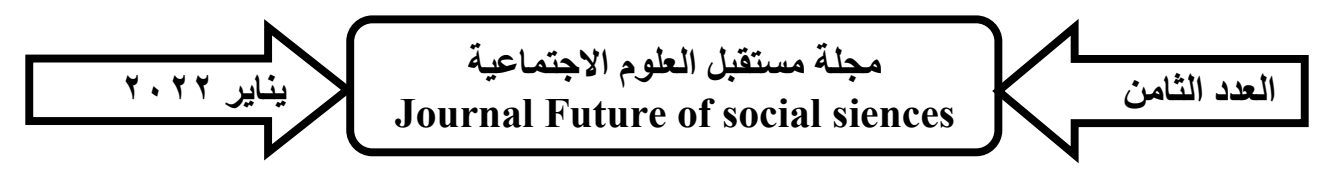

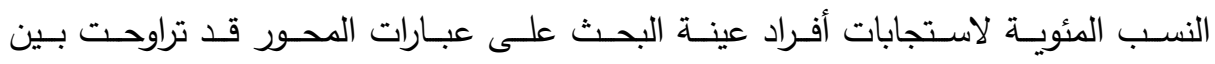

$$
\begin{aligned}
& \text { (\% } \% \text {. . } \% \text { r \% } \% \vee . r q) \\
& \text { الاستنتاجات والتوصيات: } \\
& \text { استنتاجات البحث }
\end{aligned}
$$

لخصت نتائج هذا البحث وفي ضوء المنهج المستخدم وفي حدود العينة وأدوات جمع البيانات

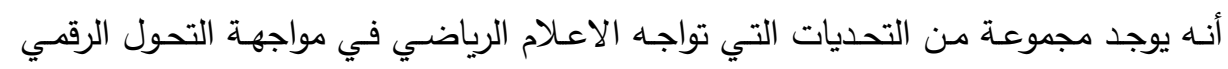
الحديث حيث أن جميع المحاور التي تم تحديدها قد أجابت على كثير من التساؤلات التي

وضعها الباحث أمامكم وأثبت البحث أن هناك حلول لهذه التحديات وعلاج لها ولذلك فإن: أولا: أهم التحديات وفقا للنتائج: - التحديات التي واجهت المؤسسات الإعلامية تجاه تطور التحول الرقمي بالنسبة للعاملين والإمكانات التقنية.

- التحديات العلمية والعملية التي واجهت المؤسسات والافراد. ثانيا: الحلول المقترحة وفقا للنتائج: - عمل دورات تدريبية للعاملين بمجال الاعلام الرياضي لمواكبة التطور التكنولوجي الحديث. - العمل على تجهيز المؤسسات الإعلامية بالتكنولوجيا الحديثة وتدريب العاملين عليها. - المحور الأول ثقافة التحول الرقمي: ا- زيادة الوعي لاى أفراد المجتمع بمعرفة ما هو التحكم الرقمي وما هي استخداماته. r- تطوير أداء العاملين في مجال التحول الرقمي الحديث عن طريق دورات تدربية للحفاظ على وظائفهم. - المحور الثاني ثقافة الاعلام الرياضي: ا - تخديد الرؤيسة والرسـالة الخاصين بالإعلام الرياضـي للحث على مواجهة التحول الرقهي الحديث.

r- تطوير أداء العاملين في مجال الاعلام الرياضي على أدوات التحول الرقمي الحديثة. - المحور الثالث تقييم المتلقي: ا - العمل على تقديم أفضل الخدمات الإعلاميـة الرياضية للمتلقي عن طريق كل القنوات المتاحة. 


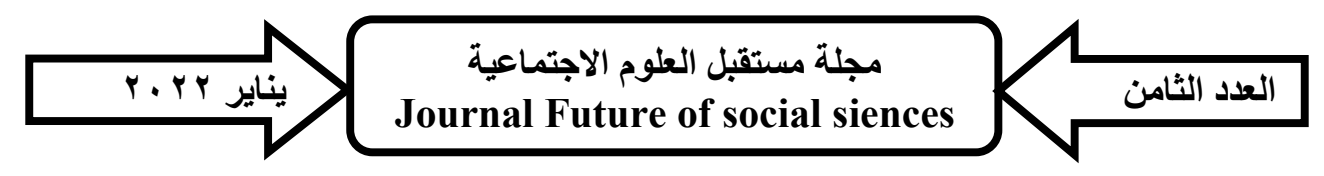

ץ- يجب على المتلقي البحث الدائم عن أسهل وأفضل الطرق للوصول إلى المعلومة والخبر

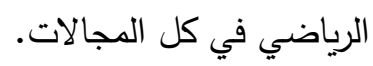
- المحور الرابع تقييم العاملين:

1- يجب توفير العمالة الخاصة بالإعلام الرياضي من خريجي كليات ومعاهد الاعلام كليات التربية الرياضية ودمجهم مع بعض للوصول لأفضل نتيجة.

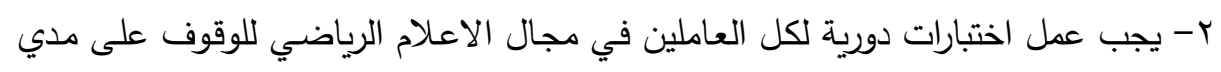

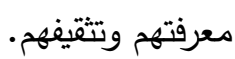

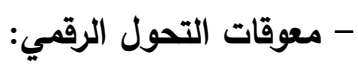

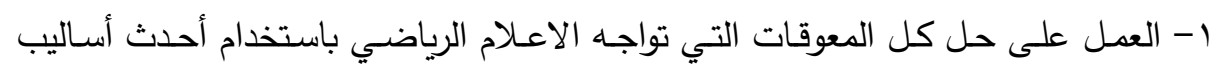
وطرق وأدوات التحول الرقمي الحديث. r- الاستعانة الدائعة بالخبراء في مجال الاعلام الرياضي للتغلب على المشاكل التي تواجه العامل والمتلقي. توصيات البحث: في ضوء النتائج السابقة توصي الدراسة بما يلي: - العمل على تطوير الأجهزة والأدوات المستخدمة في مجال الاعلام الرياضي. بلاضي.

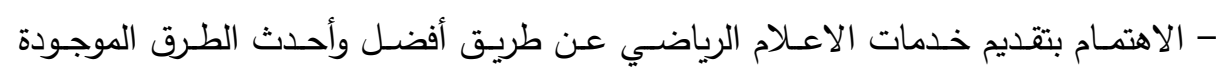
للمتلقي. - تثثيف المتلقي بما هو التحول الرقمي وما هو الاعلام الرياضي.

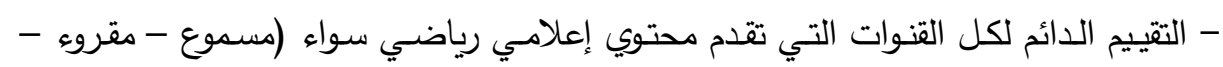

$$
\text { مرئي) }
$$

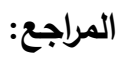

$$
\text { المراجع العربية: المراج: }
$$

التعليم الاككتروني، دار النشر والتوزيع، عمان، الأردن

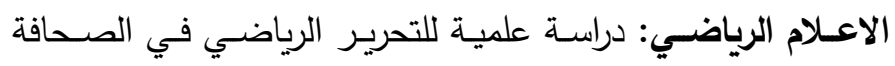

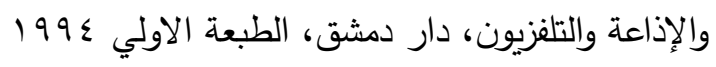

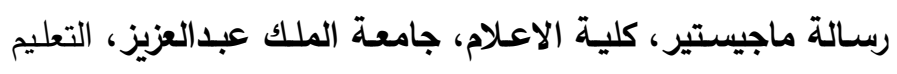

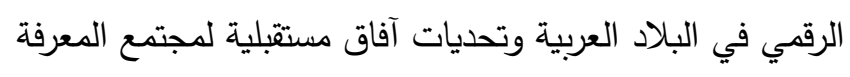

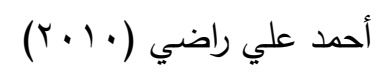

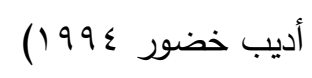

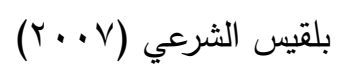




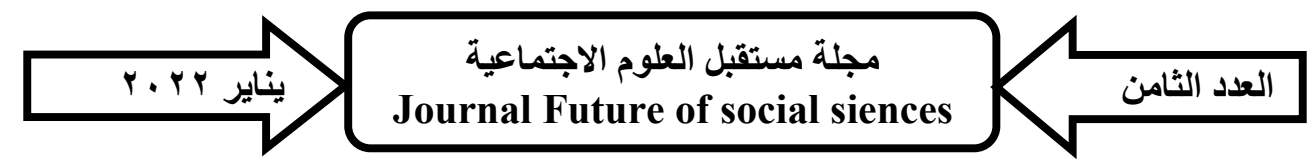

خير الدين علي عويس، عطا الاعلام الرياضي (الجزء الأول)، دار الكتاب والنثر، الطبعة الأولي حسن عبد الرحيم (1991) (191) (1991)

المعلوماتية بعد الانترنت، دار عالم المعرفة للنشر، الطبعة الأولي

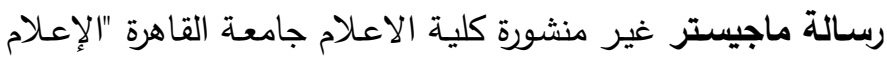

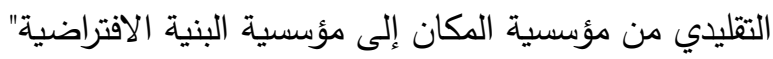
عبد السلام رضوان (1991) عبد الله محمود عدوي $(r \cdot r \cdot)$

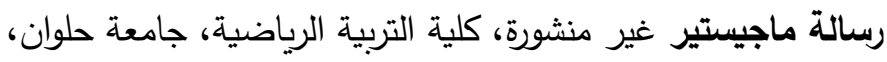
الإعلام الرياضي في توجيه الثباب نحو ممارسة الأنثطة الرياضية. عبيدة صبيح سليمان (19)

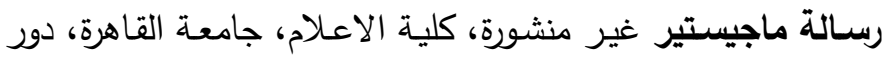

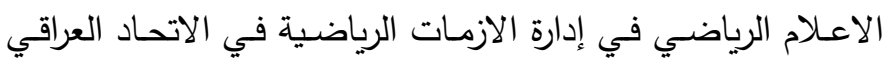
مصطفي تحمح محسن (1) المركزي لكرة القدم من وجهة نظر الدربين مقال منشور، مدخل في الاتصال والاعلام موقع جامعة محمد مطيف مقال مترجم بعنوان الاعلام الرياضي الحديث $(r \cdot r \cdot)$ موقع جامعة هارفارد

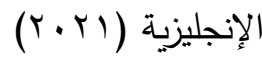
المراجع الأجنبية: الإنية (الجية

Elliot Tiffany and "Digital Transformation in Higher Mary Education. Kay, Marianne and How Content Management Technologies and Practices Laplante (2016) Lahtinen, M.and Educating for a digital future - Walking three roads Weaver, B (2015) simultaneously: one analogy and two digital " 